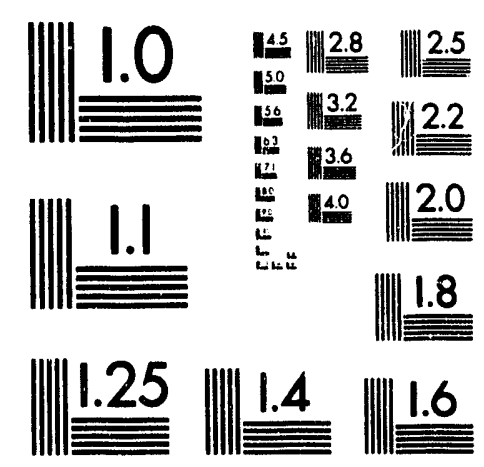



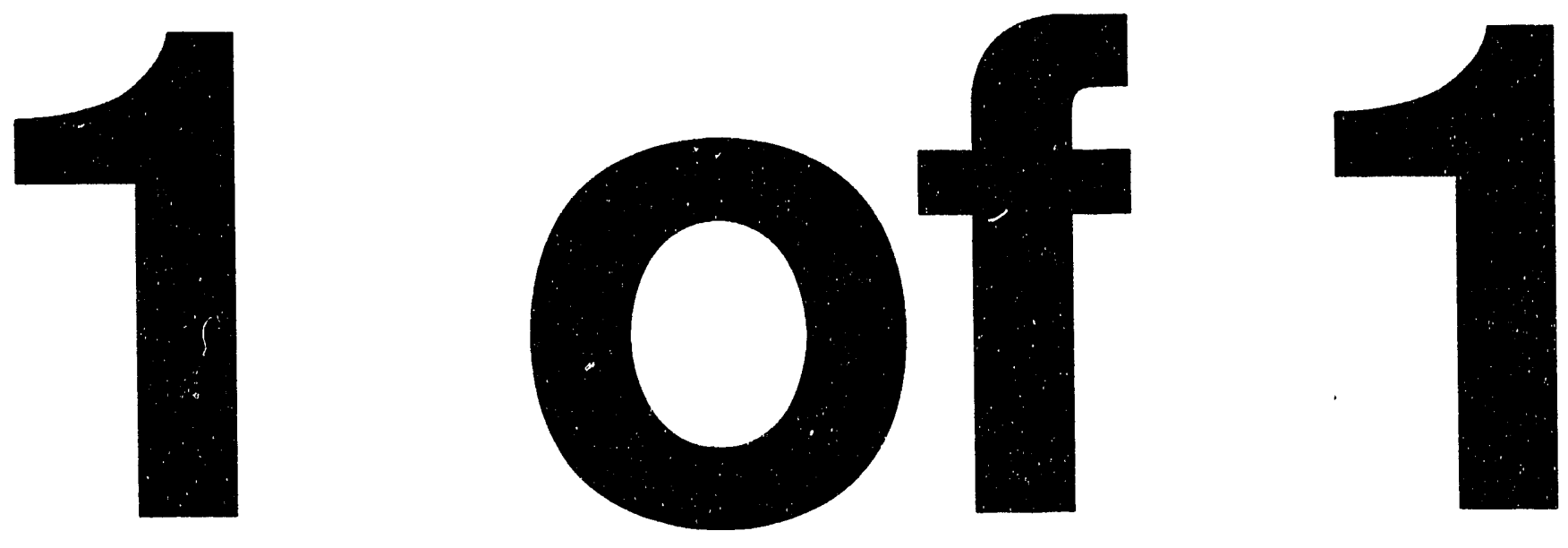
SAND93-1206

Unlimited Release

Distribution

Printed June 24, 1993

UC-705

\title{
Sandia Equation of State Data Base: seslan File
}

\author{
Gerald I. Kerley \\ Computational Physics and Mechanics Department \\ Sandia National Laboratories \\ Albuquerque, NM 87185 \\ Tracy L. Christian-Frear \\ RE/SPEC Inc. \\ 4775 Indian School Rd., NE, Suite 300 \\ Albuquerque, NM 87110
}

\begin{abstract}
Sandia National Laboratories maintains several libraries of equation of state tables, in a modified Sesame format, for use in hydrocode calculations and other applications. This report discusses one of those libraries, the seslan file, which contains 78 tables from the Los Alamos equation of state library. Minor changes have been made to these tables, making them more convenient for code users and reducing numerical difficulties that occasionally arise in hydrocode calculations.
\end{abstract}




\section{Contents}

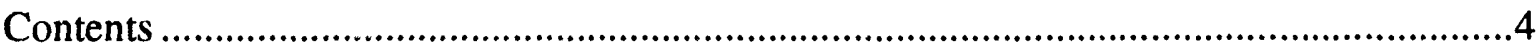

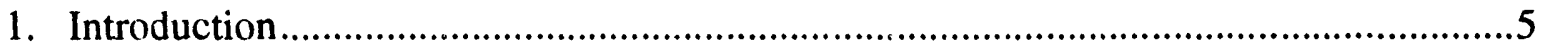

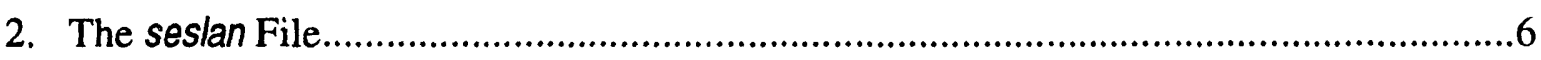

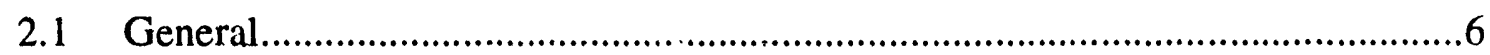

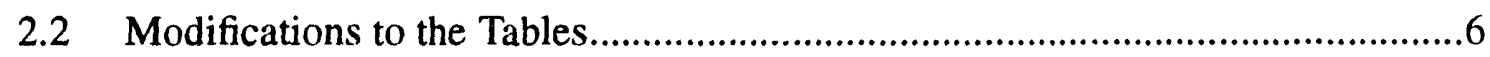

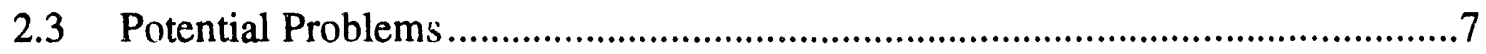

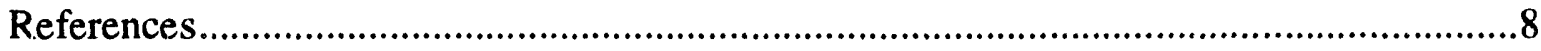

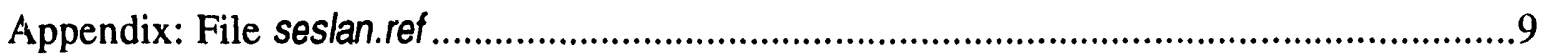

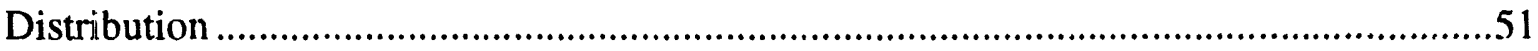




\section{Introduction}

Sandia National Laboratories (SNL) maintains a data base of tabular equations of state (EOS) for use in hydrodynamics code calculations and other applications. For example, the use of these EOS tables with the three-dimensional Eulerian code CTH [1] is described in Refs. [2] and [3]. This data base uses a modified form of the Sesame format [4] - [7], originally developed at Los Alamos National Laboratory for use in hydrocodes. Special programs, like the Panda code [4], are used to construct the EOS models and generate the tabular data. Detailed information about the Sesame format can be found in Refs. [2] - [7].

When constructing an EOS for a complicated material over a wide range of densities and temperatures, one encounters many theoretical and experimental problems that are still unsolved [8]. Many approaches can be used for this task, each having both strengths and weaknesses. As a result, there is a wide variation in the quality of EOS data available, and it can be quite difficult to assess the suitability of a particular EOS for a specific problem. This difficulty can be reduced, to some degree, by offering users a number of EOS options and by providing documentation about what is available.

Therefore, the Sandia data base maintains several files containing tabular EOS ، rata, along with documentation. The principal files are listed below:

$\begin{array}{ll}\begin{array}{l}\text { sesame } \\ \text { sesame.ref }\end{array} & \text { library of EOS tables recommended and supported by SNL } \\ \text { seslan } & \text { ASCII file of on-line information about the data on file sesame } \\ \text { seslan.ref } & \text { Aibrary of EOS tables from the Los Alamos EOS library } \\ \text { aneos } & \text { library of EOS tables made using the ANEOS package in CTH } \\ \text { aneos.ref } & \text { ASCII file of on-line information about the data on file aneos } \\ \text { jwl } & \text { library of tables made using JWL EOS for detonation products } \\ \text { jwl.ref } & \text { ASCII file of on-line information about the data on file jwI }\end{array}$

The files named sesame, seslan, aneos, and jw/ contain the EOS tables, in a sequential binary format, that are accessed and downloaded by a hydrocode during execution of a problem. The corresponding ref files provide documentation that users can consult when deciding which tables to use. All of the above files are available on the SNL Cray and on Unix workstations connected to the 1431 Protected LAN, in the following directories:

$\begin{array}{ll}\text { Cray/YMP } & \text { /usr/community/gkerley } \\ \text { UNIX LAN } & \text { /u3/gkerley/libs }\end{array}$

This report discusses only two of the files in the SNL database - seslan and seslan.ref which consists of 78 EOS tables taken from the Los Alamos library and slightly modified for use in SNL hydrococies. 


\section{The seslan File}

\subsection{General}

Seventy-eight materials from the Los Alamos EOS library were chosen to be included on the seslan file. Approximately half of them are discussed in Ref. [7]. in addition to the EOS data, the Los Alamos files contain documentation in a Hollerith format. This information is kept separate in the Sandia data base, ( . ref files), making it easier for users to access and simpler to maintain on differing computer systems. It was included, along with other comments, in making the seslan.ref file, which is listed in the Appendix.

Several criteria were used in selecting the materials to be included. Many or the older EOS tables were passed up, if newer and better versions were available. However, some older versions were included if they offered features that had been omitted in the newer tahles such as Maxwell constructions in the vapor-liquid coexistence region. In addition, there are many materials for which the only existing EOS table is quite old.

Many of the materials chosen are also available on other files in the Sandia data base, giving the user a choice of which EOS to use and the possibility of performing sensitivity studies. Still other materials are presently available only on the seslan file, making it the only tabular EOS option in those cases. In either case, a user is advised to consult the documentation in the $\sim$.ref files and to be aware of limitations of the techniques that were used in making the tables. Some of the potential problems are discussed in Sec. 2.3.

\subsection{Modifications to the Tables}

The following modifications were made to the tables before adding them to file seslan. These changes are noted in the seslan.ref file, under the heading "MODIFICATIONS."

- A new reference state table (201 table) was constructed for each material, giving the density, temperature, and bulk modulus for an appropriate set of initial conditions (normally zero pressure and room temperature). These data are used for the default initial density and temperature in CTH calculations [2], so that nothing has to be specified by the user except for unusual cases. The default reference states for all materials are listed at the beginning of the seslan.ref file.

- To eliminate problems that may be encountered when extrapolating off a table at low densities and/or low temperatures, a zero density isochore and a zero temperature isotherm were added, if they did not already exist.

- For some materials, the tension region at low densities and low temperatures was thermodynamically inconsistent and gave very high sound speeds. In those cases, the pressure table was revised to minimize numerical problems that resulted from this behavior. (See the discussion in the Panda manual [4], pp. 102104.) 
The electron and ion EOS (303 and 304 tables) and the vaporization curve (401 table) have not been included in file seslan.

\subsection{Potential Problems}

A complete survey of the EOS tables on seslan, or any other file in the data base, is beyond the scope of this report. However, the comments on file seslan.ref identify any problems or limitations that were noticed during a quick check of each EOS tables. We offer the following comments to make users aware of the kinds of difficulties that may exist in some of the EOS tables in seslan and also the other data files.

- The treatment of expanded states (tension and vaporization) creates problems when contructing EOS tables. Ideally, one wishes to allow a tension region at low temperatures, for use with fracture models, while building in a vapor-liquid coexistence region (Maxwell constructions) at high temperatures [4]. Many of the tables available do not have a tension region and so will not predict any spallation; these EOS also give too lo: $\mathrm{N}$ a sound speed at the reference state, due to interpolation problems. In other cases, no Maxwell constructions have been created, so that the EOS will not describe vaporization, even at high temperatures.

- In some very old EOS tables, the room-temperature density was used as the zero pressure point on the zero-Kelvin isotherm. As a result, the predicted density at the room temperature reference state is too low in such cases. This problem has been corrected in most of the tables, but there are still some for which no new table has been created.

- A realistic treatment of phase transitions and melting has become possible only recently [8] [9]. Many of the existing tables on the seslan file do not treat melting explicitly. Phase transitions, where they occur, are often treated by simple methods.

- Most of the tables employ a very simple treatment of thermal electronic excitation and ionization. Such models will give only a crude prediction of the behavior of shock ionization in gases, for example. With some exceptions (hydrogen and deuterium) many EOS for compounds do not account for the effects of molecular dissociation. Such tables are only valid over a limited range $\mathrm{cf}$ densities and temperatures. 


\section{References}

[1] J. M. McGlaun, F. J. Ziegler, S. L. Thompson, L. N. Kmetyk, and M. G. Elrick, "CTH - User's Manual and Input Instructions," Sandia National Laboratories report SAND88-0523, April 1988.

[2] G. I. Kerley, "CTH Reference Manual: The Equation of State Package," Sandia National Laboratories report SAND91-0344, 1991.

[3] G. I. Kerley, "CTH Equation of State Package: Porosity and Reactive Burn Models," Sandia National Laboratories report SAND92-0553, 1992.

[4] G. I. Kerley, "User's Manual for PANDA ח: A Computer Code for Calculating Equations of State," Sandia National Laboratories report SAND88-2291, 1991.

[5] B. I. Bennett, J. D. Johnson, G. I. Kerley, and G. T. Rood, "Recent Developments in the Sesame Equation-of-State Library," Los Alamos Scientific Laboratory report LA-7130, 1978.

[6] N. G. Cooper, "An Invitation to Participate in the LASL Equation of State Library," I os Alamos Scientific Laboratory report LASL-79-62, 1979.

[7] K. S. Holian, "T-4 Handbook of Material Properties Data Bases," Los Alamos National Laboratory report LA-10160-MS, 1984.

[8] J. R. Asay and G. I. Kerley, "The Response of Materials to Dynamic Loading," Int. J. Impact Engng. 5, 69-99 (1987).

[0] G. I. Kerley, "Multiphase Equation of State for Iron," Sandia National Laboratories report SAND93-0027, 1993. 


\title{
Appendix: File seslan.ref
}

\author{
DOCUMENTATION OF DATA ON SANDIA SESLAN LIBRARY FILE \\ Gerald I. Kerloy, Division 1432 \\ $05 / 03 / 93$
}

The eeslan file contains Sesame ros tables taken from the Los Alamos data base. The 201 table was modifled to give a reference state for use in hydro calculations. In some cases, the PANDA code was used to add points at zero density and temperature and to modify the pressure and energy in the tension region.

78 Materials on File

\begin{tabular}{|c|c|c|c|c|c|c|}
\hline \multirow{3}{*}{$\begin{array}{l}\text { Material } \\
\text { Name } \\
\text { Uranium }\end{array}$} & \multirow{3}{*}{$\begin{array}{c}\text { Material } \\
\text { Number } \\
1540\end{array}$} & \multicolumn{3}{|c|}{----Reference state Properties--- } & \multirow{2}{*}{\multicolumn{2}{|c|}{$\begin{array}{l}\text { Table } \\
\text { Types }\end{array}$}} \\
\hline & & $\begin{array}{c}\text { Density } \\
(g / c c)\end{array}$ & $\begin{array}{c}\text { Temperature } \\
\text { (Kelvin) }\end{array}$ & $\begin{array}{l}\text { Sound Speed } \\
(\mathrm{km} / \mathrm{s})\end{array}$ & & \\
\hline & & 18.813 & 290.121 & 2.423 & 201. & 301. \\
\hline Beryl11um & 2020 & 1.840 & 290.121 & 8.051 & 201 & 301. \\
\hline Beryllium & 2022 & 1.850 & 290.112 & 8.050 & 201 & 301 \\
\hline Iron & 2140 & 7.798 & 290.121 & 4.572 & 201. & 301. \\
\hline Lithium & 2291 & 0.5395 & 298.000 & 4.650 & 201 & 301. \\
\hline Lithium & 2293 & 0.5315 & 298.152 & 4.709 & 201. & 301. \\
\hline Gold & 2700 & 19.151 & 290.121 & 2.923 & 201 & 301. \\
\hline silver & 2720 & 10.507 & 298.152 & 3.046 & 201 & 301 . \\
\hline Ti Alloy & 2961 & 4.447 & 298.152 & 4.912 & 201 & 301 . \\
\hline Molybdenum & 2980 & 10.176 & 290.121 & 5.013 & 201 & 301 . \\
\hline Nickel & 3100 & 8.824 & 290.121 & 4.604 & 201 & 301 \\
\hline Lead & 3200 & 11.159 & 290.121 & 2.048 & 201 & 301. \\
\hline Copper & 3330 & 8.843 & 290.121 & 3.854 & 201 & 301. \\
\hline Copper & 3333 & 8.930 & 299.976 & 3.940 & 201 & 301 . \\
\hline Copper & 3336 & 8.930 & 299.976 & 4.015 & 201 & 301 . \\
\hline Tantalum & 3520 & 16.654 & 298.12 & 3.434 & 201 & 301 . \\
\hline Tungsten & 3541 & 19.237 & 298.120 & 4.023 & 201 & 301. \\
\hline w alloy & 3542 & 17.346 & 298.120 & 4.236 & 201 & 301. \\
\hline WC & 3560 & 14.970 & 298.12 & 4.911 & 201 & 301. \\
\hline Aluminum & 3715 & 2.700 & 299.976 & 5.350 & 201 & 301 . \\
\hline Platinum & 3730 & 21.329 & 290.121 & 3.608 & 201 & 301 . \\
\hline Brass & 4100 & 8.329 & 290.121 & 3.413 & 201 & 301 \\
\hline steel & 4270 & 7.842 & 290.121 & 4.529 & 201. & 301. \\
\hline Nitrogen & 5000 & 0.8572 & 63.148 & 0.8626 & 201 & 301. \\
\hline Oxygen & 5010 & 1.262 & 54.38 & 1.036 & 201. & 301 . \\
\hline Dry AIr & 5030 & $1.218 \mathrm{E}-3$ & 298.0 & 0.3388 & 201 & 301 . \\
\hline Argon & 5172 & 1.407 & 83.8 & 0.8638 & 201 . & 301. \\
\hline Kryption & 5181 & 2.490 & 115.8 & 0.5722 & 201. & 301. \\
\hline Xenon & 5190 & $5.391 \mathrm{E}-3$ & 298.15 & 0.1770 & 201 & 301. \\
\hline Eydrogen & 5251 & $8.839 \mathrm{E}-2$ & 298.15 & 3.328 & 201. & 301 . \\
\hline Deuterium & 5263 & 0.1766 & 298.15 & 2.354 & 201. & 301. \\
\hline Neon & 5410 & 1.44 & 290.12 & 1.094 & 201. & 301. \\
\hline Mothano & 5500 & 0.4263 & 95.0 & 0.2429 & 201 & 301. \\
\hline Helium & 5760 & 0.2339 & 298.15 & 1.860 & 201. & 301. \\
\hline He11um & 5761 & 0.4 & 298.15 & 2.903 & 201. & 301. \\
\hline Dry Sand & 7100 & 2.605 & 298.152 & 3.883 & 201. & 301. \\
\hline
\end{tabular}


Sandia EOS Data Base

\begin{tabular}{|c|c|c|c|c|c|c|}
\hline Dry Clay & 7102 & 3.016 & 298.152 & 4.312 & 201 & 301. \\
\hline Nev. Alluvium & 7111 & 1.313 & 290.121 & 2.335 & 201 & 301. \\
\hline Wet Tuff & 7120 & 1.950 & 298.152 & 2.415 & 201 & 301. \\
\hline Wet Tuff & 7121 & 1.950 & 298.152 & 2.041 & 201 & 301. \\
\hline LImeatone & 7130 & 2.741 & 298.152 & 4.898 & 201 & 301. \\
\hline Water & 7150 & 1.000 & 290.121 & 1.179 & 201. & 301 . \\
\hline PolyCD2 & 7160 & 1.048 & 298.15 & 2.398 & 201 & 301. \\
\hline PolYCH2 & 7171 & 0.9160 & 298.15 & 2.563 & 201 & 301. \\
\hline PolyCH2 & 7180 & 0.9540 & 298.15 & 2.8016 & 201 & 301 . \\
\hline Tefion & 7190 & 2.152 & 298.15 & 1.591 & 201 & 301. \\
\hline PolyCD2. & 7230 & 1.093 & 298.15 & 2.436 & 201 & 301. \\
\hline salt & 7281 & 2.165 & 298.15 & 3.580 & 201. & 301. \\
\hline salt & 7282 & 2.140 & 298.152 & 3.332 & 201 & 301. \\
\hline salt & 7283 & 2.243 & 298.152 & 3.334 & 201 & 301. \\
\hline Calcite & 7330 & 2.71 & 290.11 & 5.211 & 201. & 301 . \\
\hline Calcite & 7331 & 2.712 & 298.152 & 5.125 & 201. & 301. \\
\hline Quartz & 7380 & 2.155 & 290.121 & 4.091 & 201 & 301. \\
\hline Quartz & 7381 & 2.204 & 293.16 & 3.87 & 201 & 301 . \\
\hline PolyQuartz & 7383 & 2.650 & 298.152 & 3.733 & 201 & 301. \\
\hline Polyouartz & 7385 & 2.650 & 298.152 & 3.733 & 201 & 301 . \\
\hline Fused Quartz & $73 \varepsilon 6$ & 2.204 & 298.152 & 4.137 & 201. & 301. \\
\hline w. Granite & 7390 & 2.551 & 290.12 & 1.970 & 201 & 301 . \\
\hline Alumina & 7410 & 3.961 & 290.121 & 7.758 & 201 & 301. \\
\hline Alumina & 7411 & 3.970 & 298.15 & 7.820 & 201 & 301. \\
\hline Hematite & 7440 & 5.008 & 298.152 & 6.215 & 201 & 301 . \\
\hline $\mathrm{CaO}$ & 7450 & 2.982 & 298.152 & 3.696 & 201 & 301 . \\
\hline MgO & 7460 & 3.585 & 298.152 & 6.729 & 201 & 301. \\
\hline Dolomite & 7510 & 2.823 & 298.152 & 5.382 & 201 & 301. \\
\hline Mica & 7520 & 2.621 & 290.12 & 2.193 & 201 & 301 . \\
\hline Basalt & 7530 & 2.866 & 298.152 & 5.170 & 201 & 301 \\
\hline C Phenollc & 7541 & 1.450 & 298.12 & 3.052 & 201. & 301 . \\
\hline C Phenolic & 7542 & 1.499 & 298.152 & 3.150 & 201. & 301. \\
\hline Polyurethane & 7560 & 1.013 & 290.121 & 2.073 & 201 & 301. \\
\hline Polyurethane & 7561 & 1.264 & 298.152 & 2.073 & 201 & 301. \\
\hline Polystyrene & 7590 & 0.7623 & 290.121 & 0.5538 & 201. & 301. \\
\hline Polystyrone & 7591 & 0.9918 & 298.0 & 0.3166 & 201 & 301. \\
\hline Polyetyrene & 7592 & 1.044 & 298.152 & 1.302 & 201. & 301. \\
\hline Epoxy & 7601 & 1.185 & 298.152 & 2.736 & 201. & 301 . \\
\hline Epoxy & 7602 & 1.185 & 298.129 & 1.902 & 201. & 301 . \\
\hline $\mathrm{BeO}$ & 7610 & 3.01 & 298.152 & 8.459 & 201. & 301 . \\
\hline Iucite & 7750 & 1.186 & 298.152 & 1.298 & 201 & 301. \\
\hline sylgard & 7931 & 1.037 & 298.15 & 1.884 & 201. & 301. \\
\hline
\end{tabular}

EOS NOKBER 1540

MATERIAL, Jranium ( $\mathrm{z}=92.0, A=238.03)$

SOURCE. J. Barnes, J. Rood

DATE. Nar 73

REFS. K. S. Hollan, "T-4 Handbook of Materlal Properties Data Bases," LOB Alamos National Laboratory report LA-10160-MS, 1984

COMPOSITION. 0

CODES. SESAME I, MAPLE, MAXKELL

RANGE. 101 densities, $0 ., 0.15,0.28 \ldots, 3.8 \mathrm{E}+5 \mathrm{~g} / \mathrm{cc}$, 23 temperatures, $0 ., 290.121, \ldots, 3.7 \mathrm{~EB}$ Kelvin.

MODIFICATIONS.

The 201 table was modifled to give $R R E F=18.813$, TREF=290.121, and 
$\mathrm{BREF}=110.432 \mathrm{GPa}$. The value of BREF corresponds to a sound speed of $2.423 \mathrm{~km} / \mathrm{s}$.

comarents.

- This EOS is guite old - use with caution. One deficiency is that the room temperature density has been used for the zero-k 1sotherm. The reference temperature was chosen to be 290.12 even though it does not give the correct density.

- It has a tension region for temperatures below about $1160 \mathrm{k}$.

- It is not thermodynamically consistent in the vapor-1iquid region, because the Maxwell constructions were put into the pr ssure table but not into the energy table.

- Only pressure and energy are tabulated in the 301 table. There is no entropy or free energy table.

EOS NUMBER 2020

MATERIAL. Bexy111um $(Z=4.00000, A=9.01200)$

SOURCE. J. Barnes, J. Rood

DATE. Mar 73, July 73, Aug 78, Feb 92 (modifications)

REFS. K. S. Hollan, "T-4 Handbook of Material Properties Data Bases," Los Alamos National Laboratory report LA-10160-MS, 1984 COMPOSITION. Be

CODES. SESAME I, MAPLE

RANGE. 101 densities, $0,1.44 \mathrm{E}-2,2.75 \mathrm{E}-2, \ldots, 3.69 \mathrm{E}+4 \mathrm{~g} / \mathrm{cC}$, 23 temperatures, $0,290.12,580.24,1160.5, \ldots, 3.71 \mathrm{E8}$ Kelvin. MODIFICATIONS.

- The 201 table was modifled to give RREF=1.8396, TREF=290.121, and BREF $=118.53 \mathrm{GPa}$. The value of BREF corresponds to a sound speed of $8.051 \mathrm{~km} / \mathrm{s}$.

- In the tension region, modifications were made to the 301 table at $\mathrm{T}<2320 \mathrm{~K}$ and density $<1.59 \mathrm{~g} / \mathrm{cc}$ to make pressure proportional to density and energy constant.

COMMENTS .

- The tension region (for spall) was first added on 8-24-78 by Jerry Rood at the request of Mel Thieme $(x-4)$. The tension region extets for temperatures 1 ess than $2320 \mathrm{~K}$ and for temperatures approximately between 4500 and $5700 \mathrm{~K}$.

- This EOS is quite old - use with caution. One deficiency is that room temperature density had been used for the zero-K isotherm. The reference temperature was chosen to be 290.12 oven though it does not give the correct denelty.

- Interpolation on the tables produces spurious cross-overs in the pressure isotherms for temperatures greater than $\sim 2100 \mathrm{~K}$.

- Only preseure and energy are tabulated in the 301 table. Entropy and free energy are not included.

EOS NOMBER 2022

MATERIAL. Beryllium $(Z=4, A=9.012)$

SOURCE. J. Nash (ITNL), K. Trainor

DAre. June 84 (orig data); Feb 92 (modifications)

REPS. NO'.A

COMPOSITION. Be

CODEs. Thomas-Ferml plus nuclear corrections, ACTEX (LLNL), OCCIPITAL (LLNL), SOFT SPEERE (LANL)

RANGE. 73 densities, $0 ., 1.0 \mathrm{E}-4,1.25 \mathrm{E}-4, \ldots, 1000 \mathrm{~g} / \mathrm{CC}$, 43 temperatures, $0 ., 290.112,366.7,464.2, \ldots, 1.16 \mathrm{E8}$ Kelvin. MODIFICATIONS. 
- The 201 table was modified to give RREF=1.8500, TREF=290.112, $B R E F=118.5 \mathrm{GPa}$. The value of BREF corresponds to a sound speed of about $8.05 \mathrm{~km} / \mathrm{s}$.

- A rho=0.0 1sochore and $T=0.0$ 1sotherm were added to the 301 table.

COMMENTS.

- A global equation of state which covers a wide range of densities and temperatures. The theoretical models which were used to generate the EOS are (1) a soft sphere liquid metal model at temperatures below 1 ov and at densities below the liquid density; (2) a lonization equilibrium model based on a modified saha method in expansion at temperatures between 1 and $5 \mathrm{ev}$; (3) nonideal plasma theory based on a perturbation expansion of the grand canonical partition function for the higher temperatures inexpansion (this is also the ionization equilibrium regime); (4) Thomas-Fermi electronic model with Gruneisen nuclear corrections for the compression EOS.

- A problem with this EOS $i_{s}$ that for all practical purposes it does not have a tension region ( $T<300 \mathrm{~K}$ have a negative value for pressure of $\sim E-4)$, so it will not predict fracture in dynamic calculations. In adition, the interpolation scheme does not give the correct sound speed at ambient density and temperature.

- Pressure, energy and free energy are tabulated in the 301 table.

EOS NUMBER 2140

MATERIAL, Iron $(\mathrm{Z}=26.0, A=55.850)$

SOURCE. J. Barnes, J. Rood

DATE. Aug 73

REFS. K. S. Holian, "T-4 Handbook of Materlal Properties Data Bases," Los Alamos National Laboratory report LA-10160-MS, 1984

COMPOSITION. Fe

CODES. SESAME I, MAPLE, MAXWELL

RANGE. 101 densities, $0,6.1 \mathrm{E}-2, \ldots, 1.6 \mathrm{E}+5 \mathrm{~g} / \mathrm{cc}$, 23 temperatures, $0 ., 290.121, \ldots, 3.7 \mathrm{~EB}$ Kelvin.

MODIRICATIONS.

The 201 table was modified to give RREF=7.798, TREF=290.121, and BREF $=163.032 \mathrm{GPa}$. The value of BREF corresponds to a sound speed of $4.572 \mathrm{~km} / \mathrm{s}$.

COMMINTS

- This EOS is quite old - use with caution. One deficiency is that the room temperature density has been used for the zero-k 1sotherm. The reference temperature was chosen to be 290.12 even though it does not give the correct density.

- One merit of this EOS is that it does include a treatment of the phase transition.

- It has a tension region for temperatures below about $1160 \mathrm{k}$.

- It is not thermodynamically consistent in the vapor-11quid region. because the Maxwell constructions were put into the pressure table but not into the energy table.

- Only pressure and energy are tabulated in the 301 table. There is no entropy or free energy table.

EOS NONBER 2291

MATERIAI. LIthIum $(Z=3, A=6.939)$

SOURCE. David A. Young (H-Division, LLNL)

DATE. Fob 83 (orlg data); Fob 92 (modiflcations)

REFS. David A. Young, M. Ross and F. J. Rogers, "A Tabular Equation 
of state of Lithium for Laser-Fusion Reactor studies", ILNL Report UCRL-82182 (January, 1979).

COMPOSITION. Li

CODEs. Actex, Soft Sphere Liquid Metal Model, Pseudopotential

RANGE. 46 densities, $0 ., 1.0 \mathrm{E}-4,1.25 \mathrm{E}-4, \ldots, 2.0 \mathrm{~g} / \mathrm{cC}$,

62 temperatures, $0 ., 453.736,464.18,580.22, \ldots, 3.67 \mathrm{E8}$ Kelvin. MODIFICATIONS .

- The 201 table was modified to give RREF=0.53947, TREF=298., and $B R E F=11.5 \mathrm{GPa}$. The value of BREF corresponds to a sound speed of about $4.65 \mathrm{~km} / \mathrm{s}$.

- rho=0.0 1sochore and $T=0.0$ isotherm were added to the 301 table.

COMMENTS.

- Caution - if this EOS is used at temperatures below $454 \mathrm{~K}$, use the two-state model to correct the low-temperature region. The 201 table gives a reasonable but approximate reference state.

- This equation of state ranges from 0.039 ov to 31.6 kev and from e-4 to $2.0 \mathrm{gm}$ per cc. It was designed for use in laser fusion reactor simulations, and is not sultable for computations which are expected to reach densities greater than 4-fold compressed. The models used in this eos were 1) a soft sphere liquid metal model at low temperatures ( $t<0.6 \mathrm{ev}$ ) below rho zero, 2) non-ideal plasma theory (actex) at high temperatures, and 3) a liquid metal perturbation theory based on pseudopotentials for the hot, partially-ionized liquid. Agreement of the theoretical eos with experimental isobaric data (measuring volume, enthalpy and soundspeed) and experimental kugoniot data is good.

- No zero pressure point exists in this table.

- A problem with this EOS is that it does not have a tension region, so it will not predict fracture in dynamic calculations. In addition, the interpolation scheme does not give correct sound speed at reference temperature and density.

- Only pressure and energy are tabulated in the 301 table. Entropy and free energy are not included.

EOS NUMBER 2293

MATERIAL. Lithium $(\mathrm{z}=3.00000, A=6.941)$

SOURCE. J. Boettger

DATE. Jun 88 , Feb 92 (modifications)

REPS. LA-11338-MS

COMPOSITION. Li

CODES. Grizzly, SCLMT7B

RANGE. 70 densities, $0,5.33 \mathrm{E}-7,1.066 \mathrm{E}-6, \ldots, 1.066 \mathrm{E}+4 \mathrm{~g} / \mathrm{cc}$,

38 temperatures, $0,145.1,298.15,580.2, \ldots, 1.16$ E9 Relvin. MODIFICATIONS.

- The 201 table was modifled to give RREF=0.53149, TREF=298.152, and BREF=11.471 GPa. The value of BREF corresponds to a sound speed of $4.709 \mathrm{~km} / \mathrm{s}$.

COMMENTS.

- The electronic and nuclear tables are essentially the same as for 2292. The cold curve combines adjusted lmto band structure results for rho greater than or equal to 0.9 rhoo with a LennardJones tall (faclj=4.0, ecoh=0.231 mbar-cm3). This eos is generally comparable to 2292 but includes a significant shell structure effect in the cold curve for compressions ranging from 2 to 100 .

- This EOS does not have Maxwell constructions. There is a tension 
region for tomperatures 1ese than $3190 \mathrm{~K}$.

- Negative internal onergy exist for temperatures less than TREFP.

- Pressure, energy and free energy are tabulated in the 301 table.

EOS NULBER 2700

MATERIAL. Gold $(z=79.0, A=196.967)$

SOURCE. A. IIndetrom, J. Rood

DATs. Jan 76, Aug 78, Fob 92

REFs. K. S. Bolian, "T-4 Bandbook of Material Properties Data Bases," Los Alamos Natlonal Laboratory roport IA-10160-MS, 1984, LBL-3720, UCRL-50108

COMPOSITION. Au

CODEs. SESAYR I, MAPLE, MATWELL

RANGE. 101 densition, $0 ., 0.151, .288, \ldots 3.86 \mathrm{~s}+5 \mathrm{~g} / \mathrm{cc}$,

23 temperatures, $0,290.12,580.2, \ldots \ldots 3.7188$ Kelvin.

MODIFICATIONS.

- The 201 table was modified to give RREP=19.151, TREF=290.12, and BREF $=160.46$ GPa. The 301 table predicts a sound speed of 2.923 $\mathrm{ken} / \mathrm{e}$.

- In the tenuion region modifications were made to the 301 table at $T<2320 \mathrm{~K}$ and density<16.767 $\mathrm{g} / \mathrm{cc}$ to make pressure proportional to deneity and energy constant.

conarars.

- The tonsion region (for spal1) was first added on 8-24-78 by Jorry Rood at the request of Mel Thieme $(x-4)$. The tension region exists for temperatures below $2320 \mathrm{~K}$.

- A deflciency of this zOS is that the room temperature density has been ueed for the zero-K 1øotherm. The reference temperature was chosen to be 290.12 even though it does not give the correct density.

- Interpolation on the tables produces spurious cross-overs in the presaure Isotherms for tomperatures greater than $3350 \mathrm{~K}$.

- This BOS 1s not thermodynamically consistent in the vapor-1iquid region. Maxwell constructions were put into the pressure table but not in the energy table.

- Only presaure and energy are tabulated in the 301 table. Entropy and free energy are not included.

EOS NUMBER 2720

MATERIAI. SIIver $(z=47, A=107.868)$

SOURCE. J. Johnson, $s$. Lyon

DATE. Fob 88 (orig data); Fob 92 (modiflcations)

RERS. None

COMPOSITION. Ag

CODES. GRIZZLY

RANGE. 69 densit1es, $0,1.05 \mathrm{E}-5,2.1 \mathrm{E}-5, \ldots, 2.1 \mathrm{E}+5 \mathrm{~g} / \mathrm{cc}$, 37 tomperatures, $0 ., 145.1,298.2,580.2, \ldots, 1.16 \mathrm{Eg}$ Kelvin.

MODIFICATIONS.

- The 201 table was modified to give RREF=10.507, TREF=298.152, and BREF=94.162 GPa. The value of BREF correspond to a sound speed of $3.0461 \mathrm{~km} / \mathrm{s}$.

- No changes were made to the 301 table.

congritirs.

- TPD as calculated by candide in GRIZZIY was used for the eloctronic contlbution. Chartjd nuclear model with JD Gamma (1grun=7). camref $=2.4$, dobkel $=230$, $t m e l t=1234$, dgamma $=(-4.0,-2.0)$, gameps= $(0.667,3.0)$. Cold curve from bhock data. Os-up composed of one 
straight 11.ne with $c 0=3.27$ and $s=1.55$. Clat $=1.85, \bullet$ cohkc=68.0, faclf $=0.195$. 301 table has Van der Waals 100ps. Crittcal temperature 1s $4300 \mathrm{~K}$.

- Th1s EOS has van der Waals loops and no Maxwell constructions. Hence At gives a tension region for use with fracture modol.v but does not describe vaporization correctly. It does give the correct sound speed at the reference atate.

- There is a tension region for temperatures 1ess than $3660 \mathrm{~K}$.

- Pressure, energy and free energy are tabulated in the 301 table.

.. A negative internal euergy exists for temperatures less than TREFF.

EOS NOMBER 2961

MATERIAL, ittanium AlloY $(\mathrm{z}=21.118, \mathrm{~A}=45.876)$

SOURCZ. J. Johnson, S. LYon

DATE. July 85 (orig data); Feb 9.3 (modifications)

REFS. None

COMPOSITION. $90 \% \mathrm{~T} 1,6 \% \mathrm{Al}, 4 \% \mathrm{~V}$ by weight

CODES. GRIZZLY

RANGE. 72 densities, 0.,4.45E-6,8.89E-6,..,8.89E4 g/ce,

37 temperatures, $0 ., 145.1,298.2,580.2, \ldots, 1.1689$ Kelvin. MODIFICATIONS.

- The 201 table was modified to give RREF=4.4469, TREF=298.152, and $B R E F=10.6232 \mathrm{GPa}$. The value of BREF corresponds to a sound speed of $4.9121 \mathrm{~km} / \mathrm{s}$.

- No changes were made to the 301 table.

COMAMENTS.

- Average atom modeling throughout. TFD as calculated by GRIZzLY was used for the electronlc contibution. Chartjd nuclear model. cold curve from shock data and sound velocity. Us-up composed of four straight lines (up=0.0, 0.58, 0.88, 1.66, 3.2 and us $=4.937,5.72,5.72,6.65,8.18$ ). TFD match made at compression of 1.64. ECOH=112 kCal per mole and FACLJ=1.0. Special gamma (1g run=7) with gamref=1.3, gameps=0.5, 1.0 and dgamma=-0.8,-0.8. Depyeref $=400 \mathrm{~K}$.

- This EOS does not have Maxwell constructions. There 1s a tension region for temperatures 108 s than approximately $7665 \mathrm{~K}$.

- Negative Internal energy exists for temperatures less than TREFF.

- Pressure, energy and free energy are tabulated in the 301 table.

BOS NOLBER 2980

MATERIAL. Molybdenum $(Z=42, A=95.940)$

SOURCE. J. Barnes, J. RoOd

DATE. Mar 73 (orig data); Feb 92 (modifications)

REPS. R. S. Holian, " $\mathrm{T}-4$ Handbook of Material Properties Data Bases," Los Alamos National Laboratory roport LA-10160-MS, 1984

COMPOSITION. MO

CODES. Serame I, Maple, Maxwe 11

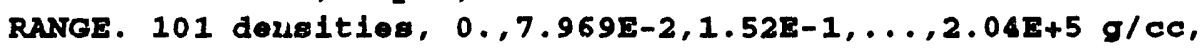
23 temperatures, $0 ., 290.12,580.24,1160.5, \ldots, 3.7188$ Kelvin.

MODIFICATIONS.

- The 201 table was modified to give RREF=10.1756, TREF=290.121, and $B R E F=254.377$ GRa. The value of BREF corresponds to a sound speed of $5.0127 \mathrm{~km} / \mathrm{s}$.

- In the tension region modifications were made to the 301 table at $T<1160 \mathrm{~K}$ and density< $9.9033 \mathrm{~g} / \mathrm{Cc}$ to make preasure proportional to density and energy constant. 
comagris .

- This EOS is quite old - use with ceition. One deficiency is that room temperature density inad been used for the zero-R 1sotherm. The reference tenperature was chosen to be 290.12 even though it does not give the correct deneity.

- There is a tension region for temperatures below $1160 \mathrm{R}$.

- This EOS is not thermodynamically consistent in the vapor-1iquid region. Maxwell constructions were put into the pressure table but not in the energy table.

- Interpolation on the tables produces spurious cross-overs in the pressure isotherms for temperatures in the approximate range of $1100<T<5840$.

- Only pressure and energy are tabulated in the 301 table. Entropy and free energy are not included.

EOS NUMBER 3100

MATERIAL. Nickel $(\mathrm{Z}=28, A=58,710)$

SOURCE. J. Barnes, J. Rood

DATE. Mar 73 (orig data); Feb 92 (modifications)

REFS. K. S. Holian, "T-4 Handbook of Materlal Properties Data Bases," Los Alamos National Laboratory report LA-10160-KS, 1984

COMPOSITION. N1

CODES. Segame I, Maple, Maxwell

RANGE. 101 densities, $0,6.939 \mathrm{E}-2,1.324 \mathrm{E}-1, \ldots, 1.776 \mathrm{E}+5 \mathrm{~g} / \mathrm{cc}$, 23 temperatures, $0 ., 25) .12,580.24,1160.5, \ldots, 3.71 E 8$ Kelvin.

MODIFICATIONS.

- The 201 table was modified to give RREF=8.8235, TREF=290.121, and BREF $=183.477 \mathrm{GPa}$. The value of BREF corresponds to a sound speed of $4.604 \mathrm{~km} / \mathrm{s}$.

- In the tension region modificatione were made to the 301 table at $\mathrm{T}<1160 \mathrm{~K}$ and density<8.151 g/cc to make pressure proportional to density and energy constant.

COMMENTS.

- This EOS is quite old - use with caution. One deficiency is that room temperature density had been used for the zero-k 1sotherm. The reference temperature was chosen to be 290.12 even though it does not give the correct density.

- It has a tension region for temperatures less than $1160 \mathrm{k}$.

- Interpolation on the tables produces spurious cross-overs in the pressure 1sotherms for temperatures greater than about $1800 \mathrm{~K}$.

- This EOS 1s not thermodynamically consistent in the vapor-1iquid region. Maxwell constructions were put into the pressure table but not in the energy table.

- Only pressure and energy are tabulated in the 301 table. Entropy and free energy are not included.

EOS NOMBER 3200

MATERIAL. Lead $(Z=82, A=207.19)$

SOURCE. J. Barnes, J. Rood

DATE. Apr 75, Aug 78 (orig data); Feb 92 (modifications)

REFS. K. S. Holian, "T-4 Handbook of Materlal Properties Data Bases," Los Alamos National Laboratory report LA-10160-MS, 1984 COMPOSITION. $\mathrm{Pb}$

CODEs. Sesame I, Maple, Maxwell

RANGE. 101 densities, $0 ., 8.86 \mathrm{E}-2,0.169, \ldots, 2.268 \mathrm{E}+5 \mathrm{~g} / \mathrm{CC}$, 23 temperatures, $0 ., 290.12,580.24,1160.5, \ldots, 3.7128$ Kelvin. 
MODIFICATIONS.

- The 201 table was modified to give RREF=11.1591, TREF=290.121, and $B R E F=45.2869 \mathrm{GPa}$. The value of BREF corresponde to a sound speed of $2.0482 \mathrm{~km} / \mathrm{s}$.

- In the tension region modifications were made to the 301 table at $T<2307 \mathrm{~K}$ and density<9.0733 g/CC to make pressure proportional to density and energy constant.

coxaghNTs.

- The tonsion rogion (for spall) was flrst added on 8-24-78 by Jerry Rood at the request of Mel Thieme $(x-4)$. The tension region exists for temperatures below $2307 \mathrm{~K}$.

- This EOS is quite old - us witl caution. One deficiency is that room temperature density had been used for the zero-k isotherm. The reference temperature was chosen to be 290.12 even though it does not give the correct density.

- This EOS is not thermodynamically consistent in the vapor-1iquid region. Maxwell constructions were put into the pressure table but not in the energy table.

- Only pressure and energy are tabulated in the 301 table. Entropy and fxee energy are not included.

EOS NOMBER 3330

MATERIAL, Copper $(Z=29.0, A=63.54)$

SOURCE. J. Barnes, J. Rood

DATE. MaY 74

REFS. R. S. Holian, "T-4 Handbook of Material Pxopert1es Data Bases," Los Alamos National Laboratory report LA-10160-MS, 1984 COMPOSITION. Cu

CODES. SESAME I, MAPLE

RANGE. 101 densities, $0,0.07,0,13 \ldots, 1.8 \mathrm{E}+5 \mathrm{~g} / \mathrm{cc}$, 23 temperatures, 0.,290.121,..,3.7E8 Kelvin.

MODIFICATIONS.

- The 201 table was modified to give $R R E F=8.8433$, TREF $=290.121$, and BREF=131.339 GPa. The value of BREF corresponds to a sound speed of $3.854 \mathrm{~km} / \mathrm{s}$.

- The low density-temperature region, rho<8.193, $t<1200 \mathrm{~K}$, was modified to make pressure proportional to density and energy constant.

comannTs.

- This EOS is quite old - use with caution. One deficiency is that the room temperature density has been used for the zero-k 1sotherm. The reference temperature was chosen to be 290.12 even though it does not give the correct density.

- It has a tension region for temperatures below about $2320 \mathrm{k}$.

- Only pressure and energy are tabulated in the 301 table. There is no entropy or free energy table.

EOS NOMGERR 3333

MATERIAL. Copper $(\mathrm{Z}=29.0, A=63.54)$

SOURCE. K. Trainor

DATE. Feb. 84

REFS. K. S. Trainor, J. Appl. Phys. 54(5), 1983.

K. S. Hollan, "T-4 Handbook of Material Properties Data Bases," Los Alamos National Laboratory report LA-10160-MS, 1984

COMPOSITION. Cu

CODES. APW, ACTEX (F. ROgerB, LLNL), OCCIPITAL (C. ROUEe, LLNL), SOFTSPHERE (D. YOung, LLWL), GRAY (R. Grover, LWWL), 
TFHOC (F. Ree, IINL)

RANGE. 74 doneitios, $0,1 . \mathrm{z}-6, \ldots, 1 . \mathrm{s}+3 \mathrm{~g} / \mathrm{Cc}$,

65 temperatures, $0 ., 299.976, \ldots, 5.8 \mathrm{~EB}$ Kelvin.

MODIFICATIONS .

The 201 table was modifled to give RREF=8.93, TREF=299.9763, and $B R E F=138.6$ GPa. The value of BREF corresponds to a sound speed COMnariss.

- EOS 3331, on which this EOS is based, is a global equation of atate which ranges from densities of $1.00-3$ to $1.00+3 \mathrm{gm}$ per cc and from ambient temperature to $5.00+4 \mathrm{ov}$. Six different theoretical models were used, a soft sphere liquid metal model at low temperatures below melt density; an lonlzation equilibrium model based on a modified Saha method at moderate temperatures in expansion; a nonideal plasma theory for high temperatures; a modified Thomas-Fermi-Kirzhnits model In compression; rigorous electron band theory for zero degree isotherm; and a semi-empirical model in the solid-1iquid-vapor region. Agreement with existing experimental data (including soviet release isentrope data) 18 excellent.

- EOS 3333 is an extension of sesame 3331 downward in density from $1.00-3 \mathrm{~g} / \mathrm{CC}$ to $1.00-6 \mathrm{~g} / \mathrm{CC}$. A saha model was used for the extension at temperatures above $0.316 \mathrm{ev}$. Below that temperature we used the soft sphere model for liquid metals developed by Devid Young at IINL. In addition, a pseudo curve was added to the table by logarithmically extrapolating the pressures and energies down rrom the lowest two finite temperature isotherms. A zero density 1sochore was also put in -- the pressures were set to zero, and the energy was calculated by extrapolating down linearly from the two lowest density points in the table.

- A problem with this gos is that it has no tension region, so it will not predict fracture in dynamic calculations. In addition, the interpolation scheme does not give the correct sound speed at ambient density and temperature.

- Only pressure and energy are tabulated in the 301 tabje. There is no entropy or free energy table.

EOS NOYBER 3336

MATERIAI. COPper $(\mathrm{z}=29.0, A=63.54)$

SOURCE. K. Hollan

DATE. Obtained from LANL in Mar 91

REFS. none

COMPOSITION. $\mathrm{Cu}$

cones.

RANGE. 74 densities, $0,1 . \mathrm{E}-6, \ldots, 1 . \mathrm{E}+3 \mathrm{~g} / \mathrm{Cc}$,

65 temperatures, 0.,299.976,..,5.8E8 Kelvin.

MODIFICATIONS.

The 201 table was modified to give RREF=8.93, TREF=299.9763, and $\mathrm{BREF}=143.975 \mathrm{GPa}$. The value of BREF corresponds to a sound speed COMarints.

- Th1s EOS 18 11ke 3333 except that it has a tonsion region at low temperatures and densities near normal, for treatment of fracture in dynamic calculations. Interpolation on the table does give a reasonable value for the sound speed.

- Only pressure and energy axe tabulated in the 301 table. There 1s no entropy or free energy table.

EOS NOMEER 3520 
MATERIAL. Tantalum $(z=73.0, A=180.948)$

SOURCE. B. Bennett

DATE. Fob 83 (orlg data); Fob 92 (modiflcatlons)

REFS. Hugdata, Sandia Iaboratories Report SC-RR-70-28

CONPOSITION. Ta

CODES. EOSCRAY, CANDIDE

RANGE. 49 densities, $0 ., 1.68,1.81, \ldots, 42.929 \mathrm{~g} / \mathrm{cc}$,

16 tomperatures, $0 ., 298.12,580.22,870.34, \ldots, 6.52685$ Kelvin.

MODIFICATIONS .

- The 201 table was modified to give RREF=16.6540, TREF=298.12, and $B R E F=194.897$ GPa. The value of BREF corresponds to a sound speed of $3.4338 \mathrm{~km} / \mathrm{s}$.

- No changes were made to the 301 table.

COMnEANTS.

- This EOS uses the chart-d form for gama and the debye temperature for compressions greater than one and a virlal match for compressions

1ess than one. The thermal electronic model is Thomas-Fermi-Dirac with Kohn-Sham exchange. The cold curve is generated from a linear fit to the shock data (us vsup). As a result, the EOS reproduces the shock data to an accuracy of 1 ess than $0.4 \%$ over the range of the data. It 1 s intended that this EOS be for applications under compression and not for vapor pressure calculations.

- This EOS has no Maxwell constructions. Hence it gives a tension region for use with 5 zcture models but does not describe vaporization correctly. (See above comment.) It does give the correct sound epeed at the reference state.

- There is a tension region for temperatures less than 12,524K.

- Pressure, energy and free energy are tabulated in the 301 table.

EOS NOMBER 3541

MATERIAL. Tungaten $(\mathrm{z}=74.00000, A=183.85000)$

SOURCE. B. Bennett

DATE. Sept 79

REFS. K. S. Holian, "T-4 Handbook of Material Properties Data Bases," LOB Alamos National Laboratory report LA-10160-MS, 1984

COMPOSITION. $W$

CODES. EOSLTS, CANDIDE

RANGE. 84 densities, $0 ., 1.9 \mathrm{E}-4, \ldots, 1.9 \mathrm{E}+4 \mathrm{~g} / \mathrm{CC}$,

25 temperatures, $0 ., 298.120, \ldots, 1.16 \mathrm{E} 8$ Kelvin.

MODIFICATIONS.

The 201 table was modified to give RREF=19.237, TREF=298.12, and $B R E F=311.312 \mathrm{GPa}$. The value of BREF corresponds to a sound speed of $4.0228 \mathrm{~km} / \mathrm{s}$.

COMDEFr's.

- This EOS has van der Waals 100ps and no Maxwell constructions. Hence it gives a tension region for use with fracture models but does not describe vaporization correctly. It does give the correct sound speed at the reference state.

- Only pressure and energy are tabulated in the 301 table. There is no entropy or free energy table.

EOS NUMBER 3542

MATERIAL. Tungsten alloy $(\mathrm{Z}=67.31600, A=165.78000)$

SOURCE. K. Holian

DATE. recelved from LANL in Mar 91

REFS. See noter for EOS 3541 
COMPOSITION. ?

CODES. See notes for BOS 3541

RANGE. 84 densities, $0 ., 1.7 \mathrm{E}-4, \ldots, 1.7 \mathrm{E}+4 \mathrm{~g} / \mathrm{CC}$,

25 temperatures, $0,298.120, \ldots, 1.16 \mathrm{E} 8 \mathrm{Kelvin}$.

MODIFICATIONS

The 201 table was modified to give RREF=17.346, TREP=298.12, and BREF $=311.301 \mathrm{GPa}$. The value of BREF corresponds to a sound speed of $4.2363 \mathrm{~km} / \mathrm{s}$.

COMMENTS .

- This EOS has van der Waals 100ps and no Maxwell constructions. Hence it gives a tension region for use with fracture models but does not describe vaporization correctly. It does give the correct sound speed at the reference state.

- Only pressure and energy are tabulated in the 301 table. There 1s no entropy ox free energy table.

EOS NUMBER 3560

MATERIAL. Tungsten Carbide $(z=38.75335311, A=94.19088602)$

SOURCE. R. Albers

DATE. Nov 81 (orlg data); Feb 92 (modificationg)

REFS. None

CODES. TFD, EOSO 422

RANGE. 100 densities, $0 ., 1.5 \mathrm{E}-4,1.8 \mathrm{E}-4, \ldots, 1.5 \mathrm{E} 4 \mathrm{~g} / \mathrm{CC}$,

25 tomperatures, $0 ., 298.12,580.23,1160.45, \ldots, 3.48 \mathrm{E} 8$ Kelvin.

MODIFICATIONS .

The 201 table was modified to give RREF=14.9699, TREF=298.12, and BREF=359.30 GPa. The value of BREF corresponds to a sound speed of $4.911 \mathrm{~km} / \mathrm{s}$.

- No changes were made to the 301 table.

COMMENTS.

- The author warns: "When comparing to experimental shock data, note that low pressure data is bad because of fast longitudinal sound waves closing gaps before the shock wave arrives."

- This EOS does not have Maxwell constructions. There is a tension region for temperatures $108 \mathrm{~s}$ than $13,350 \mathrm{k}$. Vaporization is not described correctly.

- The correct sound speed at the reference state needs to be checked (ok by SQRT (bref/ref)).

- Pressure, energy and free energy are tabulated in the 301 table.

EOS NUMBER 3715

MATERIAL. Aluminum $(\mathrm{z}=13.0, A=26.9815)$

SOURCE. Kathy Trainor

DATE. DEC 83

REFS. K. S. Trainor, "A New Full-Range Equation of state for Aluminum"

In H-Division Quarterly Report (April through June, 1982) Lawrence Livermore National Laboratory Report UCID-118574-82-2 (1982)， p.20.

R. S. Hollan, "T-4 Handbook of Material Properties Data Bases,"

Los Alamos National Laboratory report LA-10160-MS, 1984

COMPOSITION. AI

CODES. APW, ACTEX (F. RogerB, LLNL), OCCIPITAL (C. ROUBe, LLWL), SOFTSPHERE (David Young, LLNL), GRAY (R. Grover, LINL), Psuedopotential code from Marvin Ross, ILNL.

RANGE. 100 densities, $0,1, E-6, \ldots, 1 . E+3 \mathrm{~g} / \mathrm{CC}$, 
53 temperatures, $0 ., 299.976, \ldots, 1.2 \mathrm{E8}$ Kelvin.

MODIFICATIONS.

The 201 table was modified to glve RREF=2.70, TREF=299.9763, and BREF=77.28 GPa. The value of BREF corresponds to a sound speed of $5.35 \mathrm{~km} / \mathrm{s}$.

COLARINTS.

- EOS 3712, on which this EOS 18 based, is a global equation of state whlch ranges from densities of $1.00-3$ to $1.00+3 \mathrm{gm}$ per cc and from amblent temperature to $5.0 e+4 \mathrm{eV}$. Seven different theoretical models were used: a soft sphere liquid metal model at low temperatures below melt density; an lonization equilibrium model based on a modifiec Saha method at moderate temperature in expansion; a nonideal plasma theory for high temperatures; a Thomas-Fermi-kirzhnits model corrected for thermal ion contributions in compression; rigorous electron band theory for the zero degree isotherm; a semi-empirical model in the solid-11quid-vapor region; and liquid metal perturbation theory based on pseudopotentials for the hot, dense, partially Ionized liquid. Agreement with existing experimental data is excellent.

- Eos table 3715 is an extension of sesame 3712 downward in density from $1.00-3 \mathrm{~g} / \mathrm{cc}$ to $1.00-6 \mathrm{~g} / \mathrm{cc}$. A Saha model was used for the extension at temperatures above $0.4 \mathrm{eV}$, and the soft sphere model for liquid metals, developed by Dave Young at LLNL was used at the lower temperatures. In addition, a pseudo cold curve was added to the table by logarithmically extrapolating the pressures and energies down from the lowest two finite temperature isotherms. A zero density isochore was also put in -- the pressures were set to zero and the energy was calculated by extrapolating down linearly from the two lowest density points in the table.

- A problem with this EOS is that it has no tension region, so it will not predict fracture in dynamic calculations. In addition, the interpolation scheme does not give the correct sound speed at ambient density and temperature.

- Only pressure and energy are tabulated in the 301 table. There is no entropy or free energy table.

EOS NOMBER 3730

MATERIAL, Platinum ( $Z=78, A=195.09$ )

SOURCE. J. Barnes, J. Rood

DATE. Oct 72 (orig data); Feb 92 (modifications)

REFS. K. S. Holian, "T-4 Handbook of Material Properties Data Bases," LOs Alamos National Laboratory report LA-10160-MS, 1984

COMPOSITION. PE

CODES. Sesame I, Maple, Maxwe11

RANGE. 101 densities, $0,0.167,0.319, \ldots, 2.142 \mathrm{E4} \mathrm{g} / \mathrm{cc}$,

23 temperatures, $0,290.121,580.24,1160.48, \ldots, 3.7158$ Ke1vin.

MODIFICATIONS.

- The 201 table was modifled to give RREF=21.329, TREF=290.121, and $B R E F=274.798 \mathrm{GPa}$. The value of BREF corresponds to a sound speed of $3.6078 \mathrm{~km} / \mathrm{s}$.

- In the tension region modifications were made to the 301 table at $T<2330 \mathrm{~K}$ and density<18.725 $\mathrm{g} / \mathrm{Cc}$ to make pressure proportional to density and energy constant.

COMNENTS.

- This EOS is quite old - use with caution. One deficiency is that room temperature density had been used for the zero-K isotherm. The reference temperature was chosen to be 290.121 
oven though it does not give the corject density.

- There 18 a tension region for temperatures below $2330 \mathrm{~K}$.

- This zOS is not thermodynamically consistent in the vapor-1iquid region. Maxwell constructions were put into the pressure table but not in the energy table.

- Interpolation on the tables produces epurious cross-overs in the pressure isotherms for temperatures in the approximate range of $1500<T<2740$.

- Only pressure and energy are tabulated in the 301 table. Entropy and free energy are not included.

\section{EOS NUMBER 4100}

MATERIAL, BrasB $(z=29.777, A=65.334)$

SOURCE. J. Barnes, A. Lindstrom

DATE. May 76, Aug 78 (orig data); Feb 92 (modifications)

REFS. K. 3. Hollan, "T-4 Handbook of Material Properties Data Bases,"

Los Alamos National Laboratory report LA-10160-MS, 1984

COMPOSITION. $\mathrm{Cu}(61.5 \%) \mathrm{zn}(36 \%) \mathrm{Pb}(2.5 \%)$ by weight

CODES. Sesame I, Maple, Maxwel1, Mod-Morse

RANGE. 101 densities, $0 ., 6.6 \mathrm{E}-2,0.126, \ldots, 1.69 \mathrm{E5} \mathrm{g} / \mathrm{Cc}$,

23 temperatures, $0,290.121,580.24,1160.48, \ldots, 3.71 \mathrm{E8}$ Kelvin.

MODIFICATIONS.

- The 201 table was modified to give RREF=8.32913, TREF=290.121, and $B R E F=92.886 \mathrm{GPa}$. The value of BREF corresponds to a sound speed of $3.4129 \mathrm{~km} / \mathrm{s}$.

- In tho tension region modifications were made to the 301 table at $T<1500 \mathrm{~K}$ and density $<7.464 \mathrm{~g} / \mathrm{cc}$ to make pressure proportional to density and energy constant. A rho $=0.0$ isochore was added to the 301 table.

comangNTs .

- The tension region (for apall) was first added on 8-24-78 by Jerry Rood at the request of Mel Thieme (X-4). The tension region exists for temperatures below $2320 \mathrm{~K}$.

- This EOS Is quite old and should be used with caution. One deficiency is that room temperature density had been used for the zero-k isotherm. The reference temperature was chosen to be 290.12 even though it does not give the correct density.

- Only pressure and energy are tabulated in the 301 table. Entropy and free energy are not included.

EOS NOMBER 4270

MATERIAL. Stainless steel $(z=25.802, A=55.365)$

SOURCE. A. Lindatrom

DATE. ApI 76

REFS. K. S. Holian, "T-4 Handbook of Material Properties Data Bases," Los Alamos National Laboratory report LA-10160-MS, 1984

COMPOSITION. 70.0 wt\% $\mathrm{Fe}, 19.0$ wt\% $\mathrm{Cr}, 11.0$ wt\% N1

CODES. SESAME I, MAPLE, MAXWELL

RANGE. 101 densities, $0,6.2 \mathrm{E}-2,0.118, \ldots, 1.6 \mathrm{E}+5 \mathrm{~g} / \mathrm{cc}$, 23 temperatures, 0.,290.121,..,3.7 E8 Kelvin.

MODIFICATIONS.

The 201 table was modified to give RREF=7.8422, TREF=290.121, and $B R E F=160.893 \mathrm{GPa}$. The value of BREF corresponds to a sound speed of $4.529 \mathrm{~km} / \mathrm{s}$.

- A rho=0 isochore was added to the table.

- The low density-temperature region, rho<7.244, $t<1200 \mathrm{~K}$, was modified 
to make pressure proportlonal to density and energy constant. comprasts.

- This FOS is quite old - use with caution. One deficiency is that the room temperature density has been used for the zero-k Lotherm. The reference temperature was chosen to be 290.12 even though it does not give the correct density.

- Another problem is that the lowest density is quite high, $0.06 \mathrm{~g} / \mathrm{cc}$.

- It has a tension region for temperatures below about $2320 \mathrm{~K}$.

- Only pressure and energy are tabulated in the 301 table. There is no entropy or free energy table.

EOS NOMBER 5000

MATERIAL. Nitrogen $(\mathrm{z}=7, \mathrm{~A}=14.0067)$

SOURCE. G. Kerley, J. Abdallah

DATE. Apr 81, Feb 83 (orig data); Mar 92 (modifications)

REPS. JCP 73, 5337 (1980)

COMPOSITION. N2

CODES. PANDA (no dissociation or electronic terms included)

TUTTI code used to add the solid region.

RANGE. 64 densities, $0 ., 1.0 \mathrm{E}-8,3.16 \mathrm{E}-8, \ldots, 1.0 \mathrm{E} 4 \mathrm{~g} / \mathrm{cc}$,

26 temperatures, $0 ., 31.57,63.15,100, \ldots, 1.0 \mathrm{Es}$ Kelvin.

MODIFICATIONS.

- The 201 table was modified to give RREF=0.857226 g/cc, TREF=63.148K, $P R E F=1.2464 \mathrm{E}-5 \mathrm{GPa}$ and $\mathrm{BREF}=0.358256 \mathrm{GPa}$ (triple point values from SESAME 5001). The value of BREF corresponds to a sound speed of $0.86262 \mathrm{~km} / \mathrm{s}$.

- A rho=0.0 isochore was added to the 301 table.

COMMENTS.

- This gos was constructed for the molecular species only and is not valid in regions where dissociation is important, at temperatures above $10,000 \mathrm{~K}$ or pressures above $30 \mathrm{GPa}$. Data points are included outside the range of validity to prevent extrapolation problems. The 301 table was replaced (Feb 83) to correct low-temperature high-density crossing isotherms.

- This EOS does not have Maxwell constructions.

- It does give the correct sound speed at the reference state.

- There is a tension region for temperatures less than 115K.

- A negative internal energy exists for temperatures less than TREFF.

- This EOS is quite old and should be used with caution.

- Pressure, energy and free energy are tabulated in the 301 table.

EOS NUMBER 5010

MATERIAL, Oxygen $(\mathrm{Z}=8, \mathrm{~A}=16)$

SOURCE. G. Kerley, J. Abdallan

DATE. Apr 81, Feb 83 (orig data); Mar 92 (modifications)

REFS. JCP 73, 5337 (1980)

COMPOSITION. 02

CODES. PANDA (no dissociation or electronic terms included)

TUTTI code was used to add the solid region.

RANGE. 64 densities, $0,1.0 \mathrm{E}-8,3.16 \mathrm{E}-8, \ldots, 1.0 \mathrm{E} 4 \mathrm{~g} / \mathrm{CC}$,

26 temperatures, $0 ., 31.57,63.15,100, \ldots, 1.028$ Kelvin.

MODIFICATIONS.

- The 201 table was modifled to give RREF=1.26205 g/Cc, TREF=54.38K, PREF $=1.49 \mathrm{E}-7 \mathrm{GPa}$ and $\mathrm{BREF}=0.804836 \mathrm{GPa}$ (triple point values from SESAME 5011). The value of BREF corresponds to a sound speed of $1.0361 \mathrm{~km} / \mathrm{s}$. 
- A rho=0.0 18ochore was added to the 301 table.

COMMENTS.

- Th1s gOS was constructed for the molecular apecies only and is not valid in regions where dissociation is important, at temperatures above 10,000K or pressures above $30 \mathrm{GPa}$. Data points are included outside the range of validity to prevent extrapolation problema. The 301 table was replaced (Feb 83) to correct low-temperature high-density crossing isotherms.

- This EOS does not have Maxwell constructions.

- It does give the correct sound speed at the reference atate.

- There is a tension region for temperatures less than $140 \mathrm{~K}$.

- A negative intel bal energy exists for temperatures less than TREFF.

- This EOS is quite old and should be used with caution.

- Pressure, energy and free energy are tabulated in the 301 table.

EOS NUMBER 5030

MATERIAL. DIY AIT $(\mathrm{Z}=7.37296, A=14.80304)$

SOURCE. H. C. Graboske

DATE. DeC 81 (orig data); Mar 92 (modifications)

REFS. UCID-16901

COMPOSITION. N2 [78.09\%] O2 [21.95\%] Ar[0.96\%]

CODES. Bee UCID-16901

RANGE. 22 densities, $0,1.0 \mathrm{E}-7,5.5 \mathrm{E}-7, \ldots, 15 \mathrm{~g} / \mathrm{CC}$,

32 temperatures, $0 ., 175.24,958,1740.75, \ldots, 3.48 \mathrm{E}$ Kelvin.

MODIFICATIONS .

- The 201 table was modified to give TREF=298 K, PREF=1.013E-4 GPa (STP Conditions), RREF $=1.21798 \mathrm{E}-3 \mathrm{~g} / \mathrm{cC}$ and BREF=1.00998E-4 GPa The value of BREF corresponds to a sound speed of $0.33882 \mathrm{~km} / \mathrm{s}$.

- A rho $=0.0$ isochore and $T=0.0$ isotherm were added to the 301 table. COMMENTS.

- Zero pressures do not exist in the 301 table.

- Only pressure and energy are tabulated in the 301 table. Entropy and free energy are not included.

\section{EOS NUMBER 5172}

MATERIAL. Argon $(Z=18, A=39.948)$

SOURCE. J. Wolford (LINL), K. Trainor

DATE. Jan 83 (orig data); Mar 92 (modifications)

REFS. J. Wolford and $K$. Long, "A New Theoretical BOS for Argon,"

In H-Division Quarterly Report UCID-18574-81-3, Lawrence

Livermore National Laboratory, Livermore CA 94550 (1981)

COMPOSITION. Ar

CODES. OCCIPITAL (SAHA), ACTEX (Quantum Statistical Mechanical Based on Perturbation Theory), TFNUC (Thomas-Fermi Plus Nuclear Corrections) LMTO, LNJ (Lennard-Jones 6-12), and EXPERT (Exponential-six Fluid Perturbation Theory).

RANGE. 67 densities, $0 ., 1.0 \mathrm{E}-5,1.6 \mathrm{E}-5, \ldots, 1000.0 \mathrm{~g} / \mathrm{cc}$,

59 temperatures, $0 ., 83.8,116.04,145.05, \ldots, 1.16 \mathrm{E} 8 \mathrm{Kelvin}$.

MODIFICATIONS.

- The 201 table was modified to give RREF=1.40746 g/CC, TREF=83.8 K, PREF $=6.89 \mathrm{E}-5 \mathrm{GPa}$ and $\mathrm{BREF}=0.615291 \mathrm{GPa}$, all corresponding to values at the triple point (from SESAME 5171). BREF corresponds to a sound speed of $0.86381 \mathrm{~km} / \mathrm{s}$.

- A rho=0.0 isochore, and $T=0.0$ and 83.8 isotherms were added to the 301 table.

COMAENTS. 
- The equation of state for argon is a global EOs which extends from .001 to $1 . e+4$ ev in temperature and from $1.9-5$ to $1 . \theta+3 \mathrm{gm} / \mathrm{cc}$ in density. This EOS incorporates the physics of six different theoretical models: (1) a saha model for the ideal gas, ldeal plasma and part of the ionization equilibrium regime; (2) a nonideal, guantum-statistical-mechanical theory for most of the fonization equilibrium regime; (3) a Thomas-Fermi-Kirzhnits model corrected for thermal ion contributions in compression; (4) electron band theory ewbodied in a linear muffin tin orbital (IMTO) code for the zero degree isothexm; (5) an exponential-six fluid perturbation theory for the high density fluid; and (6) an analytic fit to the lennardJones 6-12 equation of state for the neutral fluid region. Favorable comparisons exist with the following experimental data: critical point data; soviet low-pressure p-v-t data; static high preseure daca; soviet shock tube data; and Hugoniot data.

- This EOS does not have a zero pressure point.

- Only pressure and energy are tabulated in the 301 table. Entropy and free energy are not included.

EOS NUMBER 5181

MATERIAL . Krypton $(\mathrm{Z}=36, A=83.8)$

SOURCE. G. Kerley

DATE. NOV 83 (orig data); Mar 92 (modifications)

REFS. LA-8062

COMPOSITION. $\mathrm{Kr}$

CODES. PANDA, INFERNO, ERMA, TUTTIUSES

RANGE. 73 densities, $0 ., 1.0 \mathrm{E}-8,1.0 \mathrm{E}-7, \ldots, 1.0 \mathrm{E} 4 \mathrm{~g} / \mathrm{cc}$,

37 temperatures, $0 ., 38.6,77.2,115.8, \ldots, 4.0 \mathrm{E} 8$ Kelvin.

MODIFICATIONS.

- The 201 table was modified to give RREF=2.49008 g/CC, TREF=115.8K, $P R E F=0.0 \mathrm{GPa}$ and $\mathrm{BREF}=0.0957749 \mathrm{GPa}$ (TREF corresponds to the melting temperature). The value of BREF corresponds to a sound speed of $0.57223 \mathrm{~km} / \mathrm{s}$.

- A rho=0.0 isochore was added to the 301 table.

COMMENTS .

- The fluid model described in LA-8062, but with an improved model of the thermal electronic term. The saha theory was used for densities below the metalif transition, and INFERNo was used above, with a region of interpolation from 3.2 to $17.0 \mathrm{~g} / \mathrm{cc}$. Both solid and fluid phases are included.

- This EOS does not have Maxwell constructions. Hence it gives a tension region for temperatures less than $197 \mathrm{~K}$ but does not describe vaporization correctly.

- Pressure, energy and free energy are tabulated in the 301 table.

- A negative internal energy exists for temperatures 1ess than TREF.

EOS NUMBER 5190

MATERIAL. Xenon $(\mathrm{z}=54, A=131.3)$

SOURCE. G. Kerley

DATE. Nov 83 (orig data); sep 92 (modifications)

REFS . LA- 8062

COMPOSITION. Xe

CODES. PANDA, INFERNO, ERMA , TUTTI

RANGE. 67 densit1es, $0.0,1.00-6, \ldots, 5000 \mathrm{~g} / \mathrm{cc}$,

35 temperatures, $0.0,53.8,107.6, \ldots, 4.008$ Kelvin.

MODIFICATIONS. 
- The 201 table was modified to glve PREF=1.013e-4 GPa, TREF $=298.15 \mathrm{~K}$ [STP Conditions], $R R E F=0.005391 \mathrm{~g} / \mathrm{cc}$ and $B R E F=1.008790-4$ FPa. The value of BREF corresponds to a sound speed of $0.17697 \mathrm{~km} / \mathrm{s}$.

- A rho=0.0 ieochore and $\mathrm{T}=298.15$ isotherm were added to the 301 table.

comarents.

- Uses the fluid model described in LA-8062, but with a cold curve based on calculations of Mckahan and Ross, and with an improved model of the thermal electrontic term. The saha theory was used for densities below the metalilc transition, and Inferno was used above, with a region of interpolation from 4.6 to $40.0 \mathrm{~g}$ per cc. Gives good agreement with the softening of the hugoniot observed by Nellis, et. al. Bcth solid and fluid phases are included.

- There are no Maxwell constructions in the vaporization region.

- This EOS ia quite old so use with caution.

- Pressure, energy and free energy are tabulated in the 301 table.

EOS NUXBER 5251

MATERIAL, EYdrogen $(z=1, A=1.00797)$

SOURCE. R. Albors, J. Johnson

DATE. Sep 82 (oxig data); Sep 92 (modifications)

REFS. Memo dated 9-27-82 by R. Albers and J. Johnson

COMPOSITION. Natural $\mathrm{mix}$ of hydrogen lsotopes

CODES. FIXTAB3

RANGE. 50 densities, $0.0,5.00-6, \ldots .1751 .7 \mathrm{~g} / \mathrm{cc}$, 25 temperatures, $0.0,290.0,477.2, \ldots, 3.708$ Kelvin.

MODIFICATIONS.

- The 201 table was modified to give PREF=0.31349 GRa, $T R E F=298.15 \mathrm{~K}, \mathrm{RREF}=0.088385 \mathrm{~g} / \mathrm{CC}$ and $\mathrm{BREF}=0.76059 \mathrm{GPa}$. The value of BREF corresponds to a sound speed of $3.328 \mathrm{~km} / \mathrm{s}$.

COMMENTS.

- This is an isotope scaling of the corrected 5263 tables (9-27-82) to produce h2 (natural $\mathrm{mlx}$ ) tables.

- There are no kaxwell constructions in the vaporization region.

- This EOS 1s quite old so use with caution.

- Only pressure and energy are 'cabulated in the 301 table. Entropy and free energy are not included.

EOS NOMBEER 5263

MATERIAL. Deuterium $(z=1.0, A=2.014)$

SOURCE. G. Kerley

DATE. Oct 71 (rerun Sep 74) (orig data); sep 92 (modifications)

REFS. IA-4760, LA-4776

COMPOSITION. D2

CODES. D2EOS

RANGE. 50 densities, $0.0,1.00-5, \ldots, 3500 \mathrm{~g} / \mathrm{cc}$,

25 temperatures, $0.0,290.0,477.2, \ldots, 3.7 e 8$ Kelvin. MODIFICATIONS.

- The 201 table was modified to give PREF=0.31349 GRa, TREF $=298.15 \mathrm{~K}, \mathrm{RREF}=0.1766 \mathrm{~g} / \mathrm{CC}$ and $\mathrm{BREF}=0.76059 \mathrm{GPa}$.

The value of BREF corresponds to a sound speed of $2.3544 \mathrm{~km} / \mathrm{s}$. comparsts.

- A 3-phase e0s (fluid, molecular solid, metallic solid). Fluid includes dissociation and lonization. Good agreement with Lasl and 111 shock data and with static data for 11quid to 20 kbar. 
Metallic transition at 2.2 mbar agrees with 111 experiment (Phys. Rev. Lett., v41, p994). Ion table added on 12 aug 80 . We have updated the existing 5263 using code Fixtab3. The only change involved replacing one point in the energy of the 301 and 303 tables. This energy polnt at $t=5.19204$ kelvin and rho=609.4 gm per cC was changed by about $1 \%$ to prevent a negative specfic heat. For further information, see memo dated 9-27-82 by $R$ Albers and J. Johnson.

- Only pressure and energy are tabulated in the 301 table. Entropy and free energy are not included.

\section{EOS NUTBEER 5410}

MATERIAL. NeON $(Z=10, A=20.183)$

SOURCE. J. Barnes, J. Rood

DATE. Nov 75 (orig data); Sep 92 (modifications)

REFS. none

COMPOSITION. Ne

CODES. SESAME I

RANGE. 101 densities, $0.0,0.013, \ldots, 28800 \mathrm{~g} / \mathrm{cc}$,

23 temperatures, $0.0,290.12,580.2, \ldots, 3.7 e 8$ Kelvin.

MODIFICATIONS.

- The 201 table was modified to give PREF=0.37998 GPa,

TREF $=290.12 \mathrm{~K}, \mathrm{RREF}=1.44 \mathrm{~g} / \mathrm{CC}$ and $\mathrm{BREF}=1.40515 \mathrm{GPa}$.

The value of BREF corresponds to a sound speed of $1.0944 \mathrm{~km} / \mathrm{s}$.

COMnERTS .

- There are Maxwell constructions in the vaporization region.

- This EOS does not have a tension region.

- Only pressure and energy are tabulated in the 301 table. Entropy and free energy are not included.

EOS NOMBER 5500

MATERIAL. Methane $(\mathrm{z}=2, A=3.20852)$

SOURCE. G. Rerley

DATE. Jan 80 (ortg data); siep 92 (modifications)

REFS. Publication in preparation

COMPOSITION. CHA

CODES. PANDA, TUTTI

RANGE. 70 densities, $0.0,1,0 e-10, \ldots, 2.5 \mathrm{~g} / \mathrm{cc}$,

23 temperatures, $0.0,20.0,45.0, \ldots, 10000$ Kelvin.

MODIFICATIONS.

- The 201 table was modifiled to give PREF=1.013e-4 GPa, TREF $=95 \mathrm{~K}$ [ Approximate Triple Point], RREF=0.42634 g/Cc and BREF $=0.0231175 \mathrm{GPa}$. The value of BREF corresponds to a sound speed of $0.2429 \mathrm{~km} / \mathrm{s}$. A rho $=0.0$ isochore and $T=0.0$ isotherm were added to the 301 table.

comprints.

- Equilibrium eos table, has Maxwell constructions. 401 table (vaporization) included. Good agreement with experiment except near critical point.

- Since this EOS was constructed for the molecular species only, it is not valid in regions where dissociation 18 important, $1 . \theta$. above 5,000 degrees Keivin. Isotherms are Included above this temperature to prevent extrapolation problems.

- Pressure, energy and firee energy are tabulated in the 301 table.

EOS NOMBER 5760 
MATERIAL. Belium $(z=2, A=4.0026)$

SOURCE. Lawrence Livermore Laboratory

DATE. Aug 74 (orig data); sop 92 (modiflcations)

REFS. OCIR-740

CONPOSITION. He-4

CODES. SeQ VCIR-740

RAYGe, 101 densities, $0.0,1.80-3, \ldots, 4678.4 \mathrm{~g} / \mathrm{cc}$,

25 temperatures, $0.0,116,298.15, \ldots, 1.1608$ Kelvin.

MODIPICATIONS.

The 201 table was modified to give PREF=0.28858 GPa, TREF=298.15K, RREF=0.23392 $\mathrm{g} / \mathrm{CC}$ and $\mathrm{BREF}=0.555593 \mathrm{GPa}$. The value of BREF corresponds to a sound speed of $1.8601 \mathrm{~km} / \mathrm{s}$. A $T=298.15$ 1sotherm was added to the sol table.

comacents.

- There are no Maxwoll constructions in the vaporization region.

- Only pressure and energy are tabulated in the 301 table. Entropy and free energy are not included.

EOS NONGER 5761

MATERIAL, Holium $(\mathrm{z}=2, A=4.0026)$

SOURCE. R. Albers

DATR. Mar 81 (orig data); Sop 92 (modifications)

REPS. None

COMPOSITION. Be-4

CODHs. PANDA (apecially modified version)

RANGE. 38 densities, $0.0,1.00-6, \ldots, 1000 \mathrm{~g} / \mathrm{cc}$,

27 temperatures, $0.0,6,12, \ldots, 1.16 e 8$ Kelvin.

MODIPZCATIONS.

- The 201 table was modified to give PREF=1.0713 GPa, TREF=298.15 $\mathrm{K}, \mathrm{RREF}=0.4 \mathrm{~g} / \mathrm{CC}$ and $\mathrm{BREF}=2.54946 \mathrm{GPa}$.

The value of BREF corresponds to a sound speed of $2.9029 \mathrm{~km} / \mathrm{s}$.

comanss.

- This zos is quite old so use with caution.

- There are no Maxwell constructions in the vaporization region.

- This sos does not have a tension region.

- Only pressure and energy are tabulated in the 301 table. Entropy and tros energy are not included.

\section{BOS NUKBER 7100}

MATERIAI. Dry Sand $(z=9.549, A=15.124)$

SOURCE. J. Barnen, s. Lyon

DATE. June 87 (orig data); Mar 92 (modifications)

REFS. None

COMPOSITION. S102[J0\%] A1203[8.22\%] CaO[4.25\%] Fe203[4.53\%] $\operatorname{Co}[3.87 \%] \mathrm{H} 2 \mathrm{O}[3.02 \%] \mathrm{K} 2 \mathrm{O}[2.06 \%$ H $\mathrm{KO}[1.89 \%] \mathrm{SO}[0.69 \%]$

T102[0.58\%] Na20[0.58\%] by weight

CODES. GRIZZLY

RANGE. 73 deneities, $0 ., 2.6 \mathrm{E}-6,5.2 \mathrm{E}-6, \ldots, 5.2 \mathrm{R4} \mathrm{g} / \mathrm{cc}$,

37 tamperatures, $0 ., 145.06,298.15,580.24, \ldots, 1.1689$ Kelvin. MODIFICATIONS.

- The 201 table was modified to give RREF=2.60462, TREF=298.152, and BREF $=38,8555 \mathrm{GPa}$. The value of BREF corresponds to a sound speed of $3.8831 \mathrm{~km} / \mathrm{s}$.

- No changes were made to the 301 table. condarts.

- Average atora zodeling used throughout except for ldeal gas portion 
of nuclear model where ldeal mixing was used. TFD as calculated by candide in GRIZZLY was used for the electronic contribution. Chartjd nuclear model with fd gamma (igrun $=7$ ). Camref $=0.875$, gameps $=$ $(0.5,1.0)$, dgama $=(1.227,0.0)$, debkel $=849.4$, treelt $=0$. In order to obtain the cold curve, the 5 mafor components of the sand (including water of hydration), were mixed in their relative ammounts using ldeal mixing to produce a characteristic hugonlot. The us-up points taken from this curve were then $($ up, us $)=(0.0,3.875),(0.774,5.375)$, $(1.786,5.813),(2.524,6.375),(4.00,8.750)$. Conat $=1.85$, ocohkc $=$ 136.7, faclf $=0.25$. 301table has $\operatorname{van}$ der waals 100ps. Critical temperature 1s $8500 \mathrm{k}$.

- This zOS has van der Waals 100ps and no Maxwell constructions. Hence it gives a tension region for use with fracture models but does not describe vaporization correctly.

- There is a tension region for temperatures 1ess than $8050 \mathrm{~K}$.

- Pressure, energy and free energy are tabulated in the 301 table.

- A negative internal energy exists for temporatures less than TREFF.

EOS NUMBER 7102

MATERIAL, DIY C1ay $(Z=9.154, A=18.312)$

SOURCE. J. Barnes, S. Lyon

DATE. June 87 (orig data); Mar 92 (modifications)

REPS. None

COMPOSITION. S102[50.65\%] A1203[15.1\%] CaO[7.19\%]

Fe2O3[6.47\%] CO2[6.1\%] H2O[5.58\%] K2O[3.49\%] MgO[3.31\%]

Na203[0.81\%] TiO2[0.78\%] SO3[0.63\%] by weight

CODES. GRIZZLY

RANGE. 71 densities, 0, 3.02E-6,6.03E-6, ., 6.04E4 g/cc,

37 temperatures, 0.,145.06,298.15,580.24,..,1.16E9 Kelvin.

MODIFICATIONS.

- The 201 table was modified to give RREF=3.01647, TREF=298.152, and $B R E F=55.2552 \mathrm{GPa}$. The value of BREF corresponds to a sound speed of $4.3123 \mathrm{~km} / \mathrm{s}$.

- No changes were made to the 301 table. comanewrs.

- Average atom modeling used throughout except for ideal gas portion of nuclear model where ideal mixing was used. TFD as calculated by candide in GRIZZLY was used for the electronic contibution. Chartjd nuclear model with JD Gamma (1grun $=1$ ). Gamref $=1.055$, debkel $=$ 766.9, tmelt $=0$. In order to obtain the cold curve, the 5 major components of the clay (Including water of hydration) were mixed in their relative amounte to produce a characteriatic hugoniot. The usup point taken from this curve were then (up, us) $=(0.0,4.33)$, $(2.10,7.14),(3.18,9.00)$. Cmat $=1.55$, ecohkc $=129$, faclf $=0.20$. 301 table has van der Waals 100ps. Critical temperature is $6800 \mathrm{k}$.

- This EOS has van der Waals loops and no Maxwell constructions. Hence it gives a tension region for use with fracture models but does not describe vaporization correctly.

- There 1s a tension region for temperatures less than $6270 \mathrm{~K}$.

- Preseure, energy and free energy are tabulated in the 301 table.

- A negative internal energy exists for temperatures 1ess than TREFF.

EOS NOLGER 7111

MATERIAL. Nevada Alluvium ( $z=9.3659, \quad A=18.761)$

SOURCE. J. Barnes, J. Rood

DATE. Sopt 75 (orig data); Mar 92 (modificationa) 
RIFs. None

COAPOSITION. S102[71.6\%] A1203[12.1\%] B2O[4.0\%] K2O[3.5\%] CaO[2.4\%]

CODEs. srank I

by welght, plue leseer amounte of other oxides

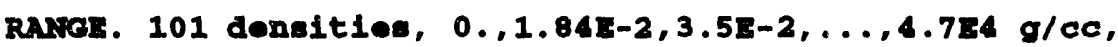

23 tomperatures, $0 ., 290.12,580.24,1160.48, \ldots, 3.7188$ Relvin.

MODIFICATIONS.

- The 201 table was modifled to give RREF=1.31285, TREF=290.121, and BREF=7.158 GPa. The value of BREF corresponds to a sound apeed of about $2.335 \mathrm{~km} / \mathrm{s}$.

- A rhom0.0 1sochore was added to the 301 table. covarants.

- Thir gos 1. quite old, wo une with caution. One deficiency 18 that room temperature density had been used for the zero-k

1sotherm. The reference temperature was chosen to be 290.12 even though it does not give the correct density.

- A problem with this zos is that it has no tension region, so it will not predict fracture in dynamic calculations. In addition, the interpolation scheme does not give the correct sound opeed at the reference state.

- Only pressure and energy are tabulated in the 301 table. Entropy and free energy are not included.

ROS NUMBER 7120

MATERIAL, Saturated Tuff $(2=6.83, A=13.4)$

SOURCE. J. Johnson, s. Lyon

DATR. May 85 (orig data); Jun 92 (modifications)

REFS. None

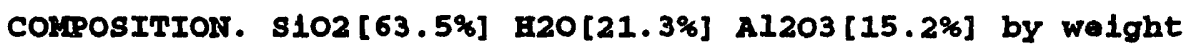

CODES. GRIZZLY

RANGE. 75 donsities, $0.0,1.95 \mathrm{z}-6, \ldots, 3.9 \mathrm{E}+4 \mathrm{~g} / \mathrm{CC}$,

37 tomperatures, $0.0,145.06,298.152, \ldots, 1.165+9$ Relvin. MODIFICATIONS.

- The 201 table was modified to give PREF=0.0 GRa, TREF $=298.152 \pi$ (STP condittons), RREF $=1.94981 \mathrm{~g} / \mathrm{CC}$ and BREF=9.94758 $\mathrm{GPa}$. The value of BREF correaponds to a sound speed of $2.415 \mathrm{~km} / \mathrm{s}$.

- No changes were made to the 301 table.

comatirs.

- This zos is for tuff with all volds fllled with water. The vold volume is $30 \%$ of the total volume. Note that even dry tuff has some water content. Average atom modeling throughout.

- TFD as calculated by GRIzZLY was used for the electronic contribution. Cold curve from shock data and sound velocity. Ds-up composed of three straight Iines (up $=0.0,1.2,2.53,6.6$ and $u_{B}=2.4,4.3,5.55,12.13$ ). Data from Ellers (private commulcation) for up $=0.0$ and $I$ sbell and Rosenberg ot al for the remaining shock data. TFD match made at compreseion of 2.16 . ecoh $=100 \mathrm{kcal}$ per mole and faclf $=0.23$. Special gamma $(1$ grun $=7)$ with ganref $=1.27$, gameps $=0.5,1.0$ and dgamma $=1.377,1.377$. This gamref was plcked botween $2 \approx-1$ and the gavef of glass. Dabyeref $=500 \mathrm{kelvin}$ (a guess).

- ThIs BOS has van der Waals loops and no Maxwell constructions. Hence it gives a tonsion region for use with fracture models but does not describe vaporization correctly.

- There 18 a teneion region for tomporatures less than $4000 \mathrm{~K}$. 
- Pressure, energy and free energy are tabulated in the 301 table.

EOS NOMBER 7121

MATERIAI. Saturated TuEf $(2=6.83, A=13.4)$

sOURCE. J. Johneon, s. Lyon

DATE. May 85 (orlg data); Jun 92 (modifications)

REPS. None

COAPOSITION. S102[63.5\%] H2O[21.3\%] A1203[15.2\%] by wolght

CODES . GRIZZLY

RANGE. 79 donaltios, $0.0,1.95 \mathrm{~s}-6, \ldots, 3.9 \mathrm{~s}+4 \mathrm{~g} / \mathrm{Cc}$,

37 temperatures, $0.0,145.06,298.152, \ldots, 1.168+9$ Kelvin.

MODIFICATIONS.

- The 201 table was modified to give PRIF=0.0 GRa,

TREF $=298.152 \times$ (STP condltions), RREF=1.94946 g/cc and

BREF=7.40064 GPa. The value of BREF corresponds to

a sound speed of $2.0411 \mathrm{~km} / \mathrm{s}$.

- No changes were made to the 301 tab1e.

COMDERTIS.

- This is the same as 7120 with the following changes: gamref = 0.9 , dgama $=(-0.3,-0.3)$, cmat $=2.19,($ up lus $)=(0.0,1.99)$, $(0.4 .2 .81),(0.7,3.20),(1.5,3.96),(2.15,4.50),(4.0,7.56)$, $(6,6,12.15)$.

- This EOS has van der Wals loops and no kaxwell constructions. Hence it gives a tension region for use with fracture models but does not describe vaporization correctly.

- There is a tension region for temperatures less than $-4000 \mathrm{~K}$.

- Pressure, energy and free energy are tabulated in the 301 table.

EOS NOMBER 7130

MATERIAL, Limestone $(Z=9.595, A=19.194)$

SOURCE. J. Barnes, S. Lyon

DATE. Jan 88 (orig data); Jun 92 (modificatlons)

REFS. None

COMPOSITION. $\mathrm{CaCO}[67.5 \%] \mathrm{s} 102[23.6 \%$ A1203[7.0\%]

H2O [1.9\%] by weight

CODES. GRIZZLY

RANGE. 72 densities, $0.0,2.74 \mathrm{z}-6, \ldots, 5.48 \mathrm{~g}+4 \mathrm{~g} / \mathrm{cc}$,

37 temperatures, $0.0,145.06,298.152, \ldots, 1.16 \mathrm{E}+9$ Kelvin. MODIFICATIONS.

- The 201 table was modified to give PREF=0.0 GPa, TREE=298.152 K (STP conditions), RREF=2.7410 g/CC and BREF=65.1092 GPa. The value of BREF corresponds to a sound speed of $4.8983 \mathrm{~km} / \mathrm{s}$.

- No changes were made to the 301 table.

COBngents.

- This table was constructed using ldeal mixing in GRIzzLY. The mixture consiats of $67.5 \%$ caco3 (7331), 23.6\% 102 (7385), $7.0 \%$ al203 (7411), 1.9\% h2o (7153) by wolght. The 301 table was rescaled to a denefty of 2.741 and has van der Waals 100 ps. critical temperature $189900 \mathrm{~K}$.

- This EOS has van der Waals loops and no vaxwell constructions. Hence it gives a tension region for use with fracture models but does not describe vaporization correctly.

- There is a tension region for temperatures leas than $-7850 \mathrm{~K}$.

- Pressure, energy and free onergy are tabulated in the 301 table. 
EOS NOXBER 7150

MATERIAL. Water $(z=3.3333, A=6.0053)$

SOURCE. F. B. ReQ (Livermore)

DATE. Jun $77 \operatorname{Jan} 78$ (orIg data); Mar 92 (modifications)

REES. UCRL 7118; F. H. Reo, "Equation of state of Water," Lawrence Ilvermore Laboratory Report UCRL-52190 (DeC 76)

COMPOSITION. H2O

CODES. See Rofa.

RANGE. 81 deneittes, $0,2.0 \mathrm{E}-6,2.5 \mathrm{E}-6, \ldots .400 \mathrm{~g} / \mathrm{CC}$, 45 temperatures, $0 ., 290.121,348.15,406.17, \ldots, 1.7488$ Kelvin. MODIFICATIONS.

- The 201 table was modified to give PREF= 0.0001013 , RREF=1.00001, TREF $=290.121$, and $B R E F=1.38433 \mathrm{GPa}$. BREF corresponds to a sound speed of $1.1794 \mathrm{~km} / \mathrm{s}$.

- A rho=0.0 18ochore and $T=0.0$ isotherm were added to the 301 table. covaresws.

- The menh for this EOS is rather coarse in some regions. It does not give a good representation of the vapor-ilquid region.

- It does not have any zero pressure polnt or tension region.

- The sound speed at the reference state is not correct.

- Only pressure and energy are tabulated in the 301 table. Entropy and free energy are not included.

EOS NOMBER 7160

KATERIAL, Deutero-Polyothylene $(z=2.6666667, A=5.3468)$

SOURCE. F. DOWe11

DATE. Sep 82 (ortg data); sep 92 (modiflcations)

REFS. IANL report to be published

COLPOSITION. CD2

CODES. FIXTAB3

RANGE. 65 donsities, $0.0,1.050-4, \ldots, 2094.9 \mathrm{~g} / \mathrm{CC}$,

32 tomperaturea, $0.0,100,200, \ldots, 1.16 e 9$ Kelvin.

MODIFICATIONS.

- The 201 table was modified to give PREP=0.0 GPa, TREF=298.15 $\mathrm{K}$ (STP conditions), RREF $=1.0475 \mathrm{~g} / \mathrm{CC}$ and $\mathrm{BREF} 5.60381 \mathrm{GPa}$. The value of BREF corresponds to a sound speed of $2.3975 \mathrm{~km} / \mathrm{s}$.

- No changes were made to the 301 table.

Comarests.

- This oos was created from 7171 by 1sotoplc scaling.

- Th1s EOS does not have Kaxwell constructions. Bence it gives a tension region for use with fracture models but does not describo vaporization correctly.

- There 1s a tension region for temperatures 1ess than 560K.

- Presøure, energy and free energy are tabulated in the 301 table.

EOS NOXBER 7171

MATERIAL, Polyothylene (branched) $(z=2.6666667, A=4.6757$ )

SOURCE. F. DOWe11

DATE. Sep 82 (orig data); sep 92 (modifications)

REFS. IA-9559-KS

COMPOSITION. CH2

CODES. CANDIDE, PANDA

RANGE. 65 donsit1es, $0.0,9.160-5, \ldots, 1832 \mathrm{~g} / \mathrm{cc}$,

32 tomperatures, $0.0,100,200, \ldots, 1.16 \bullet 9$ Kelvin.

MODIFICATIONS.

- The 201 table was modifled to give PREF=0.0 GPa, TREF=298.15 K 
(STP conditions), RREF $=0.91598 \mathrm{~g} / \mathrm{CC}$ and $\mathrm{BREF}=5.60223 \mathrm{GPa}$. The value of BREF corresponds to a sound epeed of $2.5632 \mathrm{~km} / \mathrm{a}$.

- No changes were made to the 301 table.

COMRENTS.

- This EOS does not have Maxwell constructions.

Hence it gives a tension region for use with fracture models but does not describe vaporization correctly.

- There is a tension region for temperatures $108 \mathrm{~s}$ than $560 \mathrm{~K}$.

- Pressure, energy and free energy are tabulated in the 301 table.

EOS NOMBER 7180

MATERIAL. Polyethylene (marlex) $(z=2.6666667, A=4.6757)$

SOURCE. F. DOWe11

DATE. Sep 82 (orlg data); Sep 92 (modifications)

REFS. LA-9564-MS

COMPOSITION. CH2

CODES. CANDIDE, PANDA

RANGE, 65 densities, $0.0,9.540-5, \ldots, 1908 \mathrm{~g} / \mathrm{CC}$,

32 temperatures, $0.0,100,200, \ldots, 1.1609$ Kelvin.

MODIFICATIONS.

- The 201 table was modifled to give PREF=0.0 GRa, TREF=298.15 K (STP conditions), RREF $=0.95399 \mathrm{~g} / \mathrm{CC}$ and $\mathrm{BREF}=6.76696 \mathrm{GPa}$. The value of BREF corresponds to a sound speed of $2.8016 \mathrm{~km} / \mathrm{s}$.

- No changes were made to the 301 table.

COMARENTS.

- This EOS does not have Maswell constructions.

Hence it gives a tension region for use with fracture models but does not describe vaporization correctly.

- There 1s a tension region for temperatures less than $560 \mathrm{~K}$.

- Pressure, energy and free energy are tabulated in the 301 table.

EOS NOMBER 7230

MATERIAL. Polytetradeuteroethylene $(\mathrm{z}=2.6667, A=5.3469)$

SOURCE. F. DOWe11

DATE. Aug 84 (orig data); sep 92 (modifications)

REFS. LA-10241-MS

COMPOSITION. CD2

CODES. GRIZZLY, FIXTAB

RANGE. 65 densit1.es, $0.0,1.090-6, \ldots, 2186.0 \mathrm{~g} / \mathrm{cc}$,

33 temperatures, $0.0,100,200, \ldots, 1.1609$ Kelvin.

MODIFICATIONS.

- The 201 table was modified to give PREF=0.0 GPa, TREF=298.15 K (STP conditions), $R R E F=1.0925 \mathrm{~g} / \mathrm{CC}$ and $\mathrm{BREF}=6.28365 \mathrm{GPa}$. The value of BREF corresponds to a sound speed of $2.4358 \mathrm{~km} / \mathrm{s}$.

- No changes were made to the 301 table.

COMARETS.

- ThIs EOS does not have Maxwell constructions.

Hence it gives a tension region for use with fracture models but does not describe vaporization correctly.

- There is a tension region for temperatures less than $560 \mathrm{~K}$.

- Pressure, energy and free energy are tabulated in the 301 table.

EOS NUYBER 7190

MATERIAL. Tefion $(\mathrm{z}=8, \mathrm{~A}=16.66927)$

SOURCE. F. Dowe11, J. Johnson

DATE. Aug 82 (orig data); Jul 92 (modiflcations) 
REFS. IA-9439-US

COMPOSITION. CF2

CODRS. CANDIDE, PANDA

RANaz. 64 densit1es, 0.0,2.15E-3,..,4304 g/cc,

32 temperaturea, $0.0,100,200, \ldots, 1.16 \mathrm{Eg}$ Kelvin.

MODIFICATIONS.

- The 201 table was modified to give PREF=0.0 GPa, TREF $=298.15 \mathrm{~K}$ ( $S M P$ conditions), RREF=2.152 $\mathrm{g} / \mathrm{CC}$ and $B R E F=5.2478 \mathrm{GPa}$. The value of BREF corresponds to a sound speed of $1.591 \mathrm{~km} / \mathrm{s}$.

- No changes were made to the 301 table. comarants.

- Thls zos has a tonsion region for temperatures less than $800 \mathrm{~K}$ for use with fracture models but does not describe vaporization correctly. It does give the correct sound speed at the reference state.

- Pressure, energy and free energy are tabulated in the 301 table.

EOS NUEBER 7281

MATERIAL, Salt $(z=14, A=29.2214)$

sourCE. A. Merts and N. Magee

DATE. Nov 81 (orig data); Aug 92 (modifications)

REFS. LA-5068

COMPOSITION. NaCl

CODES. EOS - A Thomas-Fermi code for electron contribution with Barnes cold curve correctlons.

RANGE. 25 densities, $0.0,2.160-6, \ldots .2 .1604 \mathrm{~g} / \mathrm{cc}$,

23 temperatures, $0.0,116.1,232.1, \ldots, 5.8 e 8$ Kelvin.

MODIFICATIONS.

- The 201 table was modifled to give PREF=0.26335 GPa, TREF=298.15K, $R R E F=2.165 \mathrm{~g} / \mathrm{CC}$ and $\mathrm{BREF}=27.6222 \mathrm{GPa}$. The value of $\mathrm{BREF}$ correaponds to a sound speed of $3.5801 \mathrm{~km} / \mathrm{s}$. $T=0.0$ and 298.151 sotherms were added to the 301 table.

coManENTS.

- Th1s zOS does not consider known phase changes at moderately low pressure. A quick attempt to fill a request from Bob Deupree.

- This EOS 1s quite old so use with caution. It does not have any tension region and ite treatment of the vaporization region is not realistic. The high value of PREF, necessitated by the treatment of the tension region, could cause problems in hydro calculations unless a two-state model is used to correct for it.

- Only pressure and energy are tabulated in the 301 table. Entropy and free energy are not included.

EOS NUMBER 7282

MATERIAL. Salt $(z=14, A=29.2214)$

SOURCE. J. Johneon, S. Lyon

DATE. Jan 88 (orig data); Aug 92 (modifications)

REFS. None

CONPOSITION. NaCl

CODES. GRIZZLY

RANGE. 73 densit1es, $0.0,2.140-6, \ldots, 4.2704 \mathrm{~g} / \mathrm{CC}$,

37 temperatures, $0.0,145.1,298.15, \ldots, 1.1609$ Kelvin. MODIFICATIONS.

- The 201 table was modified to give PREF=0.0 GPa, TREF=298.152 K (STP conditions), RREF $=2.1399 \mathrm{~g} / \mathrm{CC}$ and $\mathrm{BREF}=22.585 \mathrm{GPa}$. The value of BREF corresponds to a sound epeed of $3.3319 \mathrm{~km} / \mathrm{s}$. 
- No changes were made to the 301 table.

comarerss.

- Average atom modeling used throughout except for ideal gas portion of nuclear model where ideal mixing was used. TFD as calculated by candide in GRIZZLY was used for the electronic contribution. Chartjd nuclear model with jd gamma (igrun $=7$ ). gamref $=1.70$, debke1 $=300$, tmelt $=1074$. Dgamma $=(-3.0,-3.0)$ was adjusted to fit shock data at shock density of 0.868 . Cold curve from shock data at shock density of 2.137. Us-up composed of four atraight lines $($ up, us $)=(0.0,3.35),(1.71,5.66),(2.53,6.30),(3.18,7.64)$, $(5.0,10.1)$. Cmat $=1.98$, ocohkc $=76.7$, faclf $=0.115 .301$ table has van der Waals 100pe. Critical temperature is $3440 \mathrm{~K}$.

- This EOS has van der Waals 100ps and no Maxwell constructions. Hence it gives a tension region for use with fracture models but does not describe vaporization correctly. It does give the correct sound speed at the reference state.

- Pressure, energy and free energy are tabulated in the 301 table.

EOS NOMBER 7283

MATERIAL. Salt $(Z=14, A=29.2214)$

SOURCE. J. Johnson, S. Lyon

DATE. Jan 88 (orig data); Aug 92 (modifications)

REFS. None

COMPOSITION. NaCI (CaSO4) 0.0477

CODES. GRIZZLY

RANGE. 73 densities, $0.0,2.240-6, \ldots .4 .4804 \mathrm{~g} / \mathrm{CC}$,

37 temperatures, $0.0,145.1,298.15, \ldots, 1.16 \theta 9$ Kelvin. MODIFICATIONS.

- The 201 table was modifled to give PREF=0.0 GPa, TREF=298.152 $\mathrm{K}$ (STP conditions), RREF=2.2431 g/CC and $\mathrm{BREF}=23.6693 \mathrm{GRa}$. The value of BREF corresponds to a sound speed of $3.3335 \mathrm{~km} / \mathrm{s}$.

- No changes were made to the 301 table. COMNGENTS.

- This 1s the same as 7282 except for the following differences: zbar $=13.666$, abar $=28.404$, rhoref $=2.24$, tmelt $=1070$ ecohkc $=78$, tcrit $=3500 \mathrm{k}$.

- Th1s EOS has van der Waals loops and no Maxwell constructions. Hence it gives a tension region for use with fracture models but does not describe vaporization correctly. It does give the correct sound speed at the reference state.

- Pressuxe, energy and free energy are tabulated in the 301 table.

EOS NOMBER 7330

MATERIAL. Calcium Carbonate $(z=10.0, A=20.0179)$

SOURCE. F. H. Ree (LLNL, H-Division)

DATE. Jun 83 (orig data); Aug 92 (modifications)

REFS. F. H. Ree, "Equations of state of $\mathrm{CaCO} 3$ and 1ts Mixtures with B2O", Lawrence IIvermore National Laboratory Report OCRL-53113 (1981).

COMPOSITION. $\mathrm{CaCO} 3$

CODEs. Gray, Tiger, Cheq, Occipital, Tfnuc

RANGE. 93 densities, $0.0,1.00-6, \ldots, 1000 \mathrm{~g} / \mathrm{cc}$, 42 temperatures, $0.0,290.11,348.1, \ldots, 2.908$ Kelvin. MODIFICATIONS.

- The 201 table was modifled to give PREF=1.0130-4 GPa, TREF=290.11K (STP conditions), RREF=2.71 $\mathrm{g} / \mathrm{CC}$ and $\mathrm{BREF}=73.6 \mathrm{GRa}$. The value of 
BREFWas chosen to give about the right sound speed, $5.211 \mathrm{~km} / \mathrm{a}$. - A rho=0.0 18ochore and $T=0.0$ isotherm were added to the 301 table. COMAIENTSS.

- This is a wide-range multiphase equation of state which covers a density range between $1.00-6$ and $1.00+3 \mathrm{~g} p e x \mathrm{~cm} 3$ and $a$ temperature range between 0.025 and $2.50+4$ ev. The physical models which were used to calculate the eos are as follows: (1) gray - a semi-empirical model which calculates an 008 from the Gruneisen model for a solid, assuming that the solid is harmonic. It calcu - lates the 11quid state by modifying the solid free energy by an entropy correction associated with 1088 of order. Gray covers densities between 2.71 and $8.0 \mathrm{~g}$ per $\mathrm{cm} 3$ and temperatures from 0.025 to $1.0 \mathrm{ev}$. The solid was assumed to be in the aragonite phase. (2) Tiger-Cheq - these models were used in the low-temper -ature, low density region which is sensitive to the chemical equilibrium of $\mathrm{CaCO} 3$ and the dissociated species of Cacon. Tiger calculates the gaseous eos properties of the mixture using a bkw eos model. In the vapor-solid region, the code cheq was used to solve the equilibrium compositions of chemical species by extentof-reaction varlable method. (3) occipital - covers high-tempera -ture, low density region. $\mathrm{CaCO}$ is assumed to be completely diss -oclated into electrons, lons, and neutral atoms. The concentra -tions of each are obtained from the saha equation, and the thermodynamic properties are computed assuming that the mixtures behave like an ldeal gas. (4) Tfnuc - calculates electronic cont -ributions to the eos using Thomas-Fermi theory with Kirzhnits corrections for the wave nature of electrons and the electron exchange contribution. Nuclear contributions are calculated with a Grunelsen model at low temperature and the one-component plasma model at high temperature.

- This EOS has Maxwell constructions with no tension region. As a result, vaporization is treated correctly but the EOs will not give correct results in cases where spall should occur. Also, interpolation on the tables does not give the correct sound speed at the reference state.

- Only pressure and energy are tabulated in the 301 table. Entropy and free energy are not included.

\section{EOS NOMBER 7331}

MATERIAL. Calcite $(z=10.0, A=20.018)$

SOURCE. J. Barnes, S. Lyon

DATE. Jan 88 (orig data); Aug 92 (modifications)

REFS. None

COMPOSITION. $\mathrm{CaCO} 3$

CODES. GRIZZLY

RANGE. 72 densities, $0.0,2.710-6, \ldots, 5.42 \theta 4 \mathrm{~g} / \mathrm{CC}$,

37 temperatures, $0.0,145.1,298.15, \ldots, 1.1609$ Kelvin. MODIFICATIONS.

- The 201 table was modifled to give PREF=0.0 GPa, TREF=298.152 $\mathrm{K}$ (STP conditions), RREF $=2.7116 \mathrm{~g} / \mathrm{CC}$ and $\mathrm{BREF}=70.4604 \mathrm{GPa}$. The value of BREF corresponds to a sound speed of $5.1245 \mathrm{~km} / \mathrm{s}$.

- No changes wers made to the 301 table.

COMAMFNTS.

- Average atom modeling used throughout except for idea? gas portion of nuclear model where ldeal mixing was used. Tfd as calculated by candide in Grizzly was used for the electronic 
contribution. Chartjd nuclear model with chartd gamma (Igrun = 1 ). Gamref $=1.12$, debkel $=750$, tmelt $=1612$. Cold curve from shock data. Us-up composed of three straight lines (up, us) $=(0,0,5.13)$, $(0.86,6.30),(1.74,6.30),(3.71,9.00)$. cmat $=1.70$, ocohkc=135.6, faclf $=0.325$. 301 table has van der Waals loops. Critical temp -erature is $10,250 \mathrm{k}$.

- This EOS has van der Waals loops and no Maxwell constructions. Hence it gives a tension region for use with fracture models but does not describe vaporization correctly. It does give the correct sound speed at the reference state.

- Pressure, energy and free energy are tabulated in the 301 table.

EOS NUMBER 7380

MATERIAL Q Quartz $(z=10, A=20.028)$

SOURCE. J. Barnes, J. Rood

DATE. Aug 73 (orig data); Fob 92 (modifications)

REES . None

COMPOSITION. SIO2

CODES. Sesame I

RANGE. 101 densities, $0.0,0172, \ldots, 44080 \mathrm{~g} / \mathrm{CC}$,

23 temperatures, $0.0,290.12,580.2, \ldots, 3.7188$ Kelvin.

MODIFICATIONS .

- The 201 table was modified to give PREF=0.0 GPa, TREF=290.121 K (STP conditions), $R R E F=2.1554 \mathrm{~g} / \mathrm{CC}$ and $\mathrm{BREF}=33.8463 \mathrm{GPa}$. The value of BREF corresponds to a sound speed of $4.0905 \mathrm{~km} / \mathrm{s}$.

- In the tension region modifications were made to the 301 table at $\mathrm{T}<1160 \mathrm{~K}$ and density $<1.765 \mathrm{~g} / \mathrm{CC}$ to make pressure proportional to density and energy constant.

colorents.

- This EOS is quite old and should be used with caution. One deficiency is that room temperature density had been used for the zero-K isotherm. The reference temperature was chosen to be 290.121 even though it does not give the correct density.

- There is a tension region for temperatures below $1160 \mathrm{~K}$.

- This EOS is not thermodynamically consistent in the vapor-liguld region. Maxwell constructions were put into the pressure table but not in the energy table.

- Only pressure and energy are tabulated in the 301 table. Entropy and free energy are not included.

EOS NOMBER 7381

MATERIAL. Quartz $(Z=10, A=20.028)$

SOURCE. R. Albers

DATE. Feb 81 (orig data); Jul 92 (modifications)

REFS. None

COMPOSITION. SIO2

CODES. EOSLTS, SUBT

RANGE. 36 densities, $0.0,2.2 \mathrm{E}-4, \ldots, 22040 \mathrm{~g} / \mathrm{CC}$,

54 temperatures, $0.0,293.16,580.2, \ldots, 1.16 \mathrm{Eg}$ Kelvin.

MODIFICATIONS.

- The 201 table was modified to give PREP=0.0 GPa, TREF=293.16 K (STP conditions), RREP=2.2039 g/cc and $B R E F=31.7544 \mathrm{GPa}$. The value of BREF corresponds to a sound speed of $3.87 \mathrm{~km} / \mathrm{s}$.

- No changes were made to the 301 table.

COMLEENTS. 
- This gos 1s quite old so use with caution.

- Th1. mos has van der Wal. 100ps and no Naxwell constructicns. Bence it gives a tension region for use with fracture models but does not describe vaporization correctly. It does give the correct sound opeed at the reference state.

- There is a teneion region for temperatures 1ess than $7750 \mathrm{~K}$.

- Only pressure and energy are tabulated in the 301 table. Entropy and free onergy are not included.

EOS NOLAER 7383

NATERIAL. Polycrystal Quartz $(\mathrm{z}=10, \mathrm{~A}=20.0281)$

SOURCE. J. Johnson, S. Lyoz

DATE. Nov 84 (orig data); Ju? 92 (modifications)

REFS. None

COXPOSITION. S1O2

CODES. GRIZZLY

RANGE. 73 densities, $0.0,2.65 \mathrm{E}-6, \ldots, 53000 \mathrm{~g} / \mathrm{CC}$, 37 temperatures, $0.0,145.1,298.15, \ldots, 1.16 \mathrm{Eg}$ Kelvin.

MODIFICATIONS.

- The 201 table was modified to give PREF=0.4 GRa, TREF=298.152 K (STP conditions), RREF=2.6498 g/CC and $B R E F=36.6777$ GPa. The value of BREF corresponds to a sound speed of $3.7327 \mathrm{~km} / \mathrm{s}$.

- No changes were made to the 301 table.

COMagarsts.

- Average atom modeling throughout. TFD as calculated by Candide in GRIZZLY was used for the electronic contibution. Cold curve from shock data and sound velocities. Used Us-up composed of 3 straight 1ines, up $=0.0,1.0,2.41,4.0,26.76$ and us $=3.75,5.7,5.7,8.641,38.87$ respectively. Data from Chung and Simmons; Wackerle, Ragan, and Kcqueen; Fritz, and Hopson. Tfd matches made at a compression of 1.868 . ecoh $=146 \mathrm{kcal}$ per mole from B. Albers chartd nuclear model. Special gamma (1grun = 7) with gameps= 0.5, gamref $=0.653$, dgamma1 $=1.1227$, and dgamma2 $=0.0$. This gamma fits clata due to Wackerle and Kcqueen, Fritz, and Marsh. Debyeref = 950 kelvin from Lord and Norrow. This eos is pretty good for polycryetal quartz and only slightly less accurate for crystal quartz.

- This zos is quite old so use with caution.

- Th1s EOS has van der Waals loops and no Maxwell constructions. Hence it gives a tension region for use with fracture models but does not describe vaporization correctly. It does give the correct sound speed at the reference state.

- There is a tension region for temperatures 1ess than $7000 \mathrm{~K}$.

- Pressure, energy and free energy are tabulated in the 301 table.

EOS NOMBER 7385

MATERIAL, Polycrystal Quartz $(z=10, A=20.028)$

SOURCE. J. Barnes, $s$, Iyon

DATE. Jun 87 (orig data); Jul 92 (modifications)

REPS. None

COMPOSITION. $\mathrm{S} 102$

CODES . GRIZZLY

RANGE. 73 densities, $0.0,2.65 \mathrm{E}-6, \ldots, 53000 \mathrm{~g} / \mathrm{CC}$,

37 temperatures, $0.0,145.1,298.15, \ldots, 1.16 \mathrm{Eg}$ Kelvin.

MODIFICATIONS. 
- The 201 table was modified to give PREF=0.0 GRa, TREF $=298.152 \mathrm{~K}$ ( $\mathrm{STP}$ conditions), $\mathrm{RRHF}=2.6499 \mathrm{~g} / \mathrm{CC}$ and BREF=36.696?. GPa. The value of BREF corresponds to a sound speed of $3.7332 \mathrm{~km} / \mathrm{s}$.

- No changes were made to the 301 table.

comarents.

- This is the same as 7383 except the Chartjd nuclear model was used.

- This zos is quite old so use with caution. One deficiency is

- This EOS has van der Wals 100ps and no Maxwell constructions. Hence it gives a tension region for use with fracture models but does not describe vaporization correctly. It does give the correct sound speed at the reference state.

- There is a tension region for temperatures less than $10000 \mathrm{~K}$.

- Pressure, energy and free energy are tabulated in the 301 table.

EOS NOMBER 7386

MATERIAL. Fused Quartz $(z=10, A=20.0281)$

SOURCE. J. Boettger

DATE. Nov 88 (orig data); Jul 92 (modifications)

REFS. LA-11488-MS

COMPOSITION. S102

CODES. GRIZZLY

RANGE. 75 densities, $0.0,2.2 \mathrm{E}-6, \ldots, 44080 \mathrm{~g} / \mathrm{cc}$, 39 temperatures, $0.0,145.1,298.15, \ldots .1 .16 \mathrm{Eg}$ Kelvin. MODIFICATIONS .

- The 201 table was modified to give PREF=0.0 GRa, TREP $=298.152 \mathrm{~K}$ (STP conditions), RREF=2.204 g/CC and BREF $=37.5313 \mathrm{GPa}$. The value of BREF corresponds to a sound speed of $4.1371 \mathrm{~km} / \mathrm{s}$.

- No changes were made to the 301 table.

COMREENTS.

- The electronic contribution and the cold curve for high compressions were constructed by first applying tfd theory to each component separately and then using additive volume mixing. For compressions less than 2.1 the cold curve was derived from a 4 line fit to experimental hugoniot data defined by five (up, us ) points- $(0.00,4.09),(0.85,5.1),(2.25,5.1)$, $(2.877,5.71),(4.494,8.461)$. The expanded cold curve uses a Lennard-Jones form with faclf $=3.0$ and ecohkc $=146$. The chartjd nuclear model was used with debkel $=950$, gamref $=$ 0.65 , tmelt $=1900$. This oos 1s superior to 7381 for fused quartz. It is not intended as an oos for crystaline or polycryataline quartz.

- This EOS has van der Waals loops and no Maxwell constructions. Hence it gives a tension region for use with fracture models but does not describe vaporization correctly.

- There is a tension region for temperatures less than $\sim 6000 \mathrm{~K}$.

- Pressure, energy and free energy are tabulated in the 301 table.

EOS NONBER 7390

MATERIAL. Westerly Granite $(z=10.272, A=20.669)$

SOURCE. J. Barnes, J. Rood

DATE. Mar75, Jan 79 (orig data); Jul 92 (modifications)

REFS. None

COMPOSITION. SiO2[73.9\%] A1203[14.9\%] K2O[4.5\%] CaO[3.3\%] FeO[2.0\%]

(plus trace amounts of other oxides) by weight 
CODES. SESAME I

RANGE. 101 donsities, $0.0,0.0205, \ldots, 5.254 \mathrm{E}+4 \mathrm{~g} / \mathrm{CC}$,

23 temperatures, $0.0,290.12,580.24, \ldots, 3.71 E+8$ Kelvin.

MODIFICATIONS.

- The 201 table was modified to give PREF=1.013E-4 GRa, TREP=290.12 $\mathrm{K}$ (STP conditions), RREF=2.5505 g/CC and a sound speed of $1.9698 \mathrm{~km} / \mathrm{s}$. A rhom 0 1sochore was added to the 301 table. comagers's.

- This EOS is quite old so use with caution. One deficiency is that room temperature density had been used for the zero-k. 1sotherm. The reference temperature was chosen to be 290.12 even though it does not give the correct density.

- This EOS does not have a tension region. It does not give the correct sound speed at the reference state.

- Only pressure and energy are tabulated in the 301 table. Entropy and free energy are not included.

EOS NUMBER 7410

MATERIAL Alumina $(z=10, A=20.392)$

SOURCE. J. Barnes, J. Rood

DATE. Nov 72, Jan 79 (orig data); Jul 92 (modifications)

REFS. None

CONPOSITION. A1203

CODES. SESAME

RANGE. 101 denaities, $0.0,3.102 \mathrm{E}-2, \ldots, 3970 \mathrm{~g} / \mathrm{cc}$,

23 temperatures, $0.0,290.121,580.24, \ldots, 3.758$ Kelvin.

MODIFICATIONS.

- The 201 table was modifled to give PREF=0.0 GPa, TREF $=290.121 \mathrm{~K}, \mathrm{RREF}=3.96114 \mathrm{~g} / \mathrm{CC}$ and

BREF $=236.802 \mathrm{GPa}$. The value of BREF corresponds to

a sound epeed of $7.7584 \mathrm{~km} / \mathrm{s}$.

- A rho=0.0 18ochore was added to the 301 table.

comacints.

- This EOS 1s quite old so use with caution. One deficiency is that room temperature density had been used for the zero-K isotherm.

- This EOS has van der Waals 100ps. Honce it gives a tension region for for temperatures less than $2900 \mathrm{~K}$ to use with fracture models but does not describe vaporization correctly. It does give the correct sound apeed at the reference state.

- It appears Maxwell constructions were applied to temperatures above $2900 \mathrm{~K}$. A cross ovex of 1sochores occur at approximately $3.39 \mathrm{~g} / \mathrm{cc}$ for temperatures greator than $2900 \mathrm{~K}$.

- Only pressure and energy are tabulated in the 301 table. Entropy and free energy are not included.

EOS NOMBER 7411

MATERIAL. Alumina $(\mathrm{z}=10, A=20.392)$

SOURCE. J. Barnes, S. Lyon

DATE. Jun 87 (orlg data); Jul 92 (modifications)

REPS. IA-11058-MS

COMPOSITION. Al203

CODES. GRIZZLY

RANGE. 68 deneities, $0.0,37, \ldots 79400 \mathrm{~g} / \mathrm{CC}$,

37 tomperatures, $0.0,145.06,298.152, \ldots, 1.16 \mathrm{Eg}$ Kelvin.

MODIFICATIONS. 
- The 201 table was modified to give PREF=0.0 GRa, TREF=298.15 K (STP conditions), RREF=3.9704 g/CC and BREF=241.119 GPa. The value of BREF corresponds to a sound speed of $7.8197 \mathrm{~km} / \mathrm{s}$.

- No changes were made to the 301 table. COMangNTS .

- Average atom modeling throughout except for Ideal gas portion of nuclear model where ldeal mixing was used.

- TFD as calculated by candide in GRIZZLY was used for the electronic contibution. Chartja nuclear model with chartd Gamma (1grun=1). Gamref $=1.595$ debkel=1034, $t$ melt $=0$, . Cold curve from shock data and sound speed. Used Us-up composed of a single straight line with $\left(U_{p}, u_{8}\right)=(0.0,7.93) . \quad$ CMAT $=1.35$, ecohkc=145, faclf=0.5. 301 table has Van der Waals loops. Critical temperature is $14500 \mathrm{~K}$.

- This EOS has van der Waals loops and no Maxwell constructions. Hence it gives a tension region for use with fracture models but does not describe vaporization correctly. It does give the correct sound speed at the reference state.

- There is a tension region for temperatures less than $\sim 12500 \mathrm{~K}$.

- A negative internal energy exists for temperatures less than TREP.

- Pressure, energy and free energy are tabulated in the 301 table.

EOS NUMBER 7440

MATERIAL. Hematite $(Z=15.2, A=31.938)$

SOURCE. J. Barnes, S. LYon

DATE. Jun 87 (orig data); Aug 92 (modifications)

REFS. None

COMPOSITION. Fe2O3

CODES. GRIZZLY

RANGE. 71 denstties, $0.0,5 e-6, \ldots, 1.005 \mathrm{~g} / \mathrm{cc}$,

37 temperatures, $0.0,145.06,298.152, \ldots .1 .1609$ Kelvin. MODIFICATIONS.

- The 201 table was modified to give PREF=0 GPa, TREF=298.152 K (STP conditions), RREF=5.0079 $\mathrm{g} / \mathrm{CC}$ and $\mathrm{BREF}=191.385 \mathrm{GPa}$. The value of BREF corresponds to a sound speed of $6.215 \mathrm{~km} / \mathrm{s}$.

- No changes were made to the 301 table.

commin's.

- Average atom modeling used throughout except for Ideal gas portion of nuclear model where ideal mixing was used. Tfd as calculated by candide in grizzly was used for the electronic contribution. Chartjd nuclear model with chartd gamma (igrun = 1 ). Gamref $=1.64$, debkel $=610$, tmelt $=1838$. Cold curve from shock data and sound speed. Us-up composed of three straight lines $\left(u_{p}, u_{B}\right)=(0.0,6.243),(0.95,7.50),(2.25,7.50),(3.20,8.75)$. Cmat $=1.58$, ecohkc $=114.2$, faclj $=0.5 .301$ table has Van Der Waals loops. Critical temperature is $12,000 \mathrm{k}$.

- This EOS has van der Waals 1.00ps and no Maxwell constructions. Hence it gives a tension region for use with fracture models but does not describe vaporization correctly.

- Pressure, energy and free energy are tabulated in the 301 tablo.

EOS NOMBER 7450

MATERIAL. Calcium Oxide $(\mathrm{Z}=14, \mathrm{~A}=28.04)$

SOURCE. J. Barnes, S. Lyon

DATE. Jun 87 (orig data); Aug 92 (modifications)

REFS. None 
COFYOSITION. cao

CODEs . GRIZT2Y

RARG. 72 donelties, $0.0,2.989-6, \ldots, 5.96 e 4 \mathrm{~g} / \mathrm{cc}$,

37 temperatures, $0.0,145.05,298.152, \ldots, 1.16 e 9$ Kelvin.

MODIPICAMIOAss .

- The 201 table was modifled to give PREF=0.0 GPa, TREF=298.152 $\mathrm{K}$ (STP conditions), RREF=2.9824 $\mathrm{g} / \mathrm{CC}$ and $\mathrm{BREF}=37.7778 \mathrm{GPa}$. The value of BREF corresponds to a sound speed of $3.6963 \mathrm{~km} / \mathrm{s}$.

- No changes were mado to the 301 table.

conduarrs.

- Average atom modeling used throughout except for ldeal gas portion of nuclear model where ldeal mixing was used. Tfd as calculated by candide in grizziy was used for the electronic contribution. Chartjd nuclear model with chartd gamma (igrun = 1). Gamref $=2.40$, debkel $=640$, tmelt $=2853$. Cold curve from shock data. Us-up composed of three straight lines (up, us) = $(0.0,3.70),(2.30,7.70),(3.05,7.70),(3.55,8.55)$. Cmat $=1.72$, cohks $=126.7$, faclf $=0.25$. 301 table has van der waals 10ops. Critical temperature $439000 \mathrm{k}$.

- Thi EOS is quite old 00 use with caution.

- This EOS has van der Waals 100ps and no Maxwell constructions. Hence 1t: gives a texsion region for use with fracture models but does not deccibe vaporization correctly.

- Pressure, energy and free onergy are tabulated in the 301 table.

EOS NOYBER 7460

MATERIAL. Periclase $(z=10, A=20.156)$

SOURCE. J. Barnes, S. Lyon

DATE. Jan 88 (orig Cata); Aug 92 (modifications)

REFS. None

COMPOSITION. HgO

CODES . GRIZZIY

RANCE. 73 densities, $0,0.0,3.580-6, \ldots, 7.1764 \mathrm{~g} / \mathrm{CC}$,

37 tomperatures, $0.0 .0,145.06,298.152, \ldots, 1.16 e 9$ Kelvin.

MODIFICATIONS.

- The 201 table was modified to give PREF=0.0 GPa, TREF=298.152 K (STP conditions), $R R E F=3.5847 \mathrm{~g} / \mathrm{CC}$ and $\mathrm{BREF}=160.388 \mathrm{GPa}$. The value of BREF corresponds to a sound apeed of $6.7292 \mathrm{~km} / \mathrm{s}$.

- No changes were made to the 301 table.

colvinirs.

- Average atcm modeling used throughout excopt for ideal gas portion of nuclear model where ldeal mixing was used. Tfd as calculated by candide in grizzly was used fo: the electronic contribution. Chartjd nuclear model with chartd gama (igrun $=1$ ). camref $=1.72$, debkel $=938$, tmelt $=3125$. Cold curve from shock data. Us-up composed of one straight 11 ine with $c 0=6.78$ and $s=1.292$. Cmat $=1.98$, cobkc $=118$, faclf $=0.26 .301$ table has van der Waals loops. Critlcal temperature is $7850 \mathrm{k}$.

- Thie EOS has van der Waals 100ps and no Maxwell constructions. Hence it givs a tension region for use with fracture models but doen not descibe vaporization correctly.

- Preseure, enerigy and free energy are tabulated in the 301 tablo.

EOS NULBER 7510

MATERIAr. Dolomit.e ( $2=9,2, A=18.44)$

SOURCE. J. Johngon, S. Lyon 
DATE. Jan 88 (orig data); Aug 92 (modiflcations)

REES. None

CouposITION. Cayg $\left(\mathrm{CO}_{3}\right) 2$

CODES. GRIZZLY

RANGE. 69 densities, $0.0,2.820-6, \ldots, 5.6404 \mathrm{~g} / \mathrm{cc}$, 37 temperatures, $0.0,145.06,298.152, \ldots, 1.16 e 9$ Kelvin. MODIFICATIONS.

- The 201 table was modifled to give PREF $=0.0 \mathrm{GPa}$, IREF $=298.152 \mathrm{~K}$ ( $S T P$ conditions), RREF $=2.8229 \mathrm{~g} / \mathrm{CC}$ and $\mathrm{BREF}=80.8488 \mathrm{GPa}$. The value of BREF corresponde to sound speed of $5.3815 \mathrm{~km} / \mathrm{s}$.

- No changes were made to the 301 table. comaravis.

- Average atom modeling ueed throughout except for 1deal gas portion of nuclear model where ldeal mixing was used. Tfd as calculated by candide in grizzly was used for the electronic contribution. Chartjd nuclear model with chartd gamma (igrun = 1 ). Gamref $=1.2$, debkel $=750$, tmelt $=1300$. Cold curve from shock data. Us-up composed of one stralght 1 ine with $c 0=5.4$ and $s=1.15$. cmat $=1.70$, ecoh $=0.3$, taclf $=0.25$. 301 tablo has van der Waals 100ps. Critical temperature is $8525 \mathrm{k}$.

- This EOS has van der Waals 100ps and no Maxwell constructions. Hence it gives a tension region for use with fracture models but does not describe vaporization correctly.

- Pressure, energy and free energy are tabulated in the 301 table.

EOS NOMBER 7520

MATERIAL. MICQ $(Z=6.8697, A=13.524)$

SOURCE. J. Barnes, J. Rood

DATE. May 74 Jan 79 (oxig data); Aug 92 (modifications)

REFS. Nono

CONPOSITION. O[56.1\%] Si[16.7\%] $\mathrm{Kg}[12.6 \%] \mathrm{A} 1[7.6 \%] \mathrm{F} \bullet[4.5 \%]$

H[2.4\%] Wolght percent

CODES. SESAYE I

RANGE. 101 densities, 0.0,2.110-2,..,5.4e4 g/cc,

23 temperatures, $0.0,290.12,580.2, \ldots, 3.7108$ Kelvin.

MODIFICATIONS.

- The 201 table was modified to give PREF=1.0130-4 GRa, TREF $=290.12 \mathrm{~K}$ (STP conditions), RREF=2.6214 g/CC and $B R E F=12.5654 \mathrm{GPa}$. The value of BREF corresponds to a sound speed of $2.1925 \mathrm{~km} / \mathrm{s}$. A rho=0.0 isochore was added to the 301 table. COMPLENTS.

- This zos is quite old so use with caution. One deficiency is that room temperature density had been used for the zero-K 1sotherm. The reference tomperature was chosen to be 290.12 even though it does not give the correct density.

- Th1s gos has Maxwell constructions with no tonsion region.

- Oniy pressure and energy are tabulated in the 301 table. Entropy and tree energy are not Included.

EOS NUXBER 7530

MATERIAL. Basalt $(z=10.665, A=22.574)$

SOURCE. J. Barnes, S. Lyon

DATE. Jan 88 (orig data); Jun 92 (modifications)

REFS. Lams report in progress

COMPOSITION. O[60.11\%] $S 1[18.26 \%] \mathrm{Al}[5.96 \%] \mathrm{Ca}[4.01 \%]$

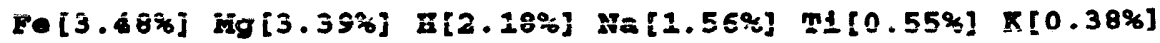


$P[0.07 \%] \mathrm{kn}[0.06 \%]$ by number

CODES. GRIZZLY

RANGE. 71 densit1es, $0.0,2.87 \mathrm{E}-6, \ldots, 5.74 \mathrm{E}+4 \mathrm{~g} / \mathrm{CC}$,

37 temperatires, $0.0,145.06,298.152, \ldots, 1.16 \mathrm{E}+9$ Kelvin.

MODIFICATIONS.

- The 201 table was modified to give PREF=0.0 GRa,

TREF $=298.152 \times$ (STP conditions), RREF=2.86594 $\mathrm{g} / \mathrm{CC}$ and

BREF=75.8994 GPa. The value of BREF corresponds to

a sound speed of $5.1704 \mathrm{~km} / \mathrm{s}$.

- No changes were made to the 301 table.

COMAENTS .

- Average atom modeling used throughout except for 1deal gas portion of nuclear model where ldeal mixing was used.

- TFD as calculated by candide in GRIZZLY was used for the -lectronic contibution. Chartfd nuclear model with charta Gamma $(1$ grun=1). Gamref $=1.17$, dobkel $=851$, tmelt $=2158$. Cold curve from shock data. Us-up composed of three straight Ilnes (up, us ) $=(0.0,5.21),(0.54,5.98),(1.75,5.98),(4.00,9.25)$. CMAT $=1.76$, ecohkc $=137$, faclf $=0.185$. The reference garma, debye tomperature and cohesive energy for the mixture were taken to be the welghted sum of the corresponding parameter values for each of the major molecular components. 301 table has van der Waals loops. Critical temperature is $6675 \mathrm{~K}$.

- This gOS has van der Waals loops and no saxwell constructions. Hence it gives a tension region for use with fracture models but does not describe vaporization correctly.

- There is a tension region for temperatures less than $\sim 5300 \mathrm{~K}$.

- Pressure, onergy and freo onergy are tabulated in the 301 table.

\section{EOS NUYBER 7541}

MATERIAL. Carbon Phono1ic $(z=4.648, A=9.0105)$

SOURCE. J. D. Johnson

DATE. Apr 81 (orig data); Mar 92 (modifications)

REFS. 111 Shock Compendium, wx-3 Kemo (9-20-79), private communication with F. Mortonson (X-2)

COMPOSITION. C[64.18\%] H[29.5\%] O[5.98\%] N[0.34\%] by moles

CODES. EOSLTS, CANDIDE

RANGE. 56 densities, $0,1.52 \mathrm{E}-3,3.03 \mathrm{E}-3, \ldots, 1.52 \mathrm{E} 3 \mathrm{~g} / \mathrm{CC}$,

25 temperatures, $0 ., 298.12,485.67,835.44, \ldots, 3.7188$ Kelvin. MODIFICATIONS.

- The 201 table was modifled to give RREF=1.45025, TREF=298.12, and BREF $=13.246 \mathrm{GRa}$. The value of BREF corresponds to a sound speed of $3.0515 \mathrm{~km} / \mathrm{s}$.

- No changes were made to the 301 table.

COMackents.

- This zos does not have Maxwell constructions. Hence it gives a tension region for use with fracture models but does not describe vaporization correctly. It does give the correct sound epeed at the reference state.

- There is a tension region for tomperaturiss 1ess than $6350 \mathrm{~K}$.

- Only pressure and energy are tabulated in the 301 table. Entropy and free energy are not included.

EOS NOYBER 7542

MATERIAL, Carbon Phenolic $(z=4.75910, A=9.25862$;

SOURCE. J. Johnson, S. Iyon 
DATE. Fob 87 (orig data); Mar 92 (modificatione)

REFS. None

COAposItION. $C[66 \%] \mathrm{B}[26.93 \%] \mathrm{O}[3.49 \%] \mathrm{N}[3.58 \%]$ by moles

CODEs. GRIZZLY

RANGE. 68 densit1es, $0,1.5 \mathrm{E}-6,3.0 \mathrm{z}-6, \ldots, 3.0 \mathrm{~g} \mathrm{~g} / \mathrm{CC}$,

37 tomperatures, $0 ., 145.06,298.15,580.24, \ldots, 1.16 \mathrm{Eg}$ Kelvin.

MODIFICATIONS

- The 201 table was modiefed to give RREF=1.49945, TREF=298.152, and $B R E F=14.7186 \mathrm{GPa}$. The value of BREF correnponds to a

sound apeed of $3.1499 \mathrm{~km} / \mathrm{s}$.

- No changes were made to the 301 table.

comprests.

- Electronic table io mix of thermal TFD for 4 elomonts. Nuclear table is from first veraion of CEARTPD (before Debye-Bucke1). Cold curve comes from shock data procedure. Os-up Input is up $=0,3.0$ with $u_{s=3.15}, 6.15$. ECOB=150 kcal per average atom mole, GAMREF $=0.5$, and $D E B R E F=1000 \mathrm{~K}$. We used IGRON=7 with GAYEPS $=0.5,1.0$ and DGAYYA= $0,0 \ldots$ The TFD match comprosetion is 2.0. The default Treis 1s used. The Eugonlot 1 s compared to data in the compendia while all other input numbere are intelilgent guesier.

- This EOS does not have Maxwell conetructions. Hence it given a tension region for use with fracture modele but doen not describe vaporization correctly. It does glve the correct sound opeed at the reference atate.

- There is a tension region for temperatures less than $7600 \mathrm{~K}$.

- A negative internal energy exist for temperatures loss than TREF.

- Pressure, energy and free energy are tabulated in the 301 table.

EOS NUMBER 7560

MATERIAL. Polyurethane $(z=3.76290, A=7.03840)$

SOURCE. J. BarneB, S. LYOn

DATE. Oct 74 Jan 79 (orig data); Mar 92 (modifications)

REES. NOne

COMPOSITION. $C[62.3 \%] O[23.3 \%]$ N [7.3\%] B[7.1\%] by weight

CODES. SESANE I

RANGE, 101 densities, $0 ., 9.9 \mathrm{E}-3,1.9 \mathrm{z}-2, \ldots .2 .53 \mathrm{E} / \mathrm{g} / \mathrm{cc}$,

23 temperatures, $0,290.121,580.24,1160.5, \ldots, 3.71 \mathrm{E} 8$ Kelvin.

MODIFICATIONS.

- The 201 table was modifled to give PREF=1.013E-4 GPa, TREF=290.12K (STP conditlons), RREF $=1.01305 \mathrm{~g} / \mathrm{CC}$ and $\mathrm{BREF}=4.35 \mathrm{GRa}$. BREF corresponds to a sound speed of $2.073 \mathrm{~km} / \mathrm{m}$.

- No changer were made to the 301 table.

comadists.

- This zos 1s quite old so use with caution. One deficiency is that room temperature denaity had been used for the zero-K 1wotherm. The reference tomperature was chosen to be 290.12 even though it does not give the correct density.

- Bohavior in the vapor-11quid region appears anomalous and 1s probably not truatworthy.

- Another problem with this sos is that it does not have a tension region, so it will not predict fracture in dymamic calculations.

- The Interpolation scheme does not give correct cound apeed at amblent temperature and density. The value in the 201 table was taken from experiment, so that som of the problem could be corrected ueing the two-state model. 
- No zero preseure values exiet in the 301 table.

- Only preveure and onergy are tabulated in the 301 table. Intropy and freo energy are not included.

LOS NOLBER 7561

YATRIAI, Polyurathane $(\mathrm{z}=3.645, A=6.782)$

sOURC:. J. Barnow, s. Lyon

DATE. Dec 88 (ortg data); Mar 92 (modiflca:1ons)

REFs. None

COAPOSITION. C[11] $\mathrm{E}[16] \mathrm{N}[1] \mathrm{O}[3]$

CODIS . ORIZZIY

RANGE. 73 donsitios, 0, 1.26z-6,2.53E-6, ., 2.53E4 g/cc,

38 temperatures, $0 ., 145.06,298.15,580.24, \ldots, 1.1629$ Kelvin.

MODIFICATIONS.

- The 201 table was modified to give PREF=1.0135-4, RREF=1.26405, TREF $=298.152$, and BREF $=5.40$ GPa. BREF corresponde to a sound epeed of $2.073 \mathrm{~km} / \mathrm{s}$.

- No changen were made to the 301 table.

covardists.

- Average atom modeling throughout except for ldeal gas portion of nuclear model where ldeal mixing was used. TFD as calculated by candide in GRIZZLY was used for the electronic contibution. CEARTJD nuclear model with CEARTD GAMLA (IGRON=1). GAMREF=1.10, DEBKEL $=167$, THas $T=450$. Cold curve from shock data and sound velocity. (up,us) polnts are $(0.0,2.068),(0.6,3.50),(2.69,6.78)$, $(3.58,7.44),(5.13,9.75)$. In order to match the critical point data, wo set ECOkKC=17 and FACLJ=0.15. In order to get a total preseure of 1 bar at room tomperature and normal density, we rescaled the cold curve using RHO0=1.31765. TFD match compression was 2.11 .

- A problem with this zos is that it does not have a tension region, so it will not predict fracture in dynamic calculations.

- The Interpolation scheme does not give correct sound speed at amblent temperature and density. The value in the 201 table was taken from experiment, so that some of the problems could be corrected using the two-state model.

- A negative internal energy exists for temperatures 1ess than TREP.

- Presaure, energy and froe onergy are tabulated in the 301 table.

EOS NOXBER 7590

MATERIAL. Polyetyrone $(z=3.5, A=6.51)$

soURCE. J. Barnes, A. Indetrom

DATE. Jan76 (orig data); Jul 92 (modiflcations)

REFS. T-4 Notebook

COMPOSITION. CH

CODES. SESAYE I, MAPLE, MAXWELL

RANGE. 101 densities, $0.0,8.156 \mathrm{E}-3, \ldots, 20880 \mathrm{~g} / \mathrm{cc}$,

23 tomperatures, $0.0,290.121,580.2, \ldots, 3.71 \mathrm{E}+8$ Kelvin. MODIFICATIONS.

- The 201 table was modified to give PREF=1.013:-4 GPa, TREF $=290.121 \times$ (STP conditions), RREF $=0.76225 \mathrm{~g} / \mathrm{cc}$ and BREF $=0.2331$ GPa. The value of BREF corresponds to a sound apeed of $0.55376 \mathrm{~km} / \mathrm{s}$.

- No changes were made to the 301 table.

covanings.

- The exieting 7590 table haw been updated using flxtab3. The 
only change involved flxing 5 energy points by a fow percent to provent crossing isotherms and negative specific heats. The range fixed was at densities between 5.2203 and 2.08804 (the $3 \mathrm{hlghest}$ densities) and temperatures between 2.3206 and 5.8006 . Fox further information, contact Bob Albers $(t-4)$.

- This BOS Is quite old so use with caution. One deficiency is that room temperature density had been used for the zero- $K$ lsotherm. The reference temperature was chosen to be 290.12 even though it does not give the correct density.

- This EOS has Maxwell constructions but no tension region. It does not give the correct sound apeed at the reference state.

- Only pressure and energy are tabulated in the 301 table. Entropy and free energy are not included.

EOS NUMBER 7591

MATERIAL. Polyotyrone $(z=3.5, A=6.51)$

SOURCE. J. Barnes, S. Lyon

DATE. Aug 86 (orig data); Jul 92 (modifications)

REFS. LAYS Report

COMPOSITION. CH

CODES . GRIZZLY

RANGE. 70 densities, $0.0,1.04 \mathrm{E}-6, \ldots, 20880 \mathrm{~g} / \mathrm{CC}$,

41 temperatures, $0.0,298,580.2, \ldots, 1.16 \mathrm{E}+9$ Kelvin.

MODIFICATIONS.

- The 201 table was modified to give PREF=0.0 GRa, TREF $=298 \mathrm{~K}$ (STP conditions), RREF=0.9918 g/CC and BREF $=0.0945 \mathrm{GPa}$. The value of BREF corresponds to a sound speed of $0.3166 \mathrm{~km} / \mathrm{s}$.

- No changes were made to the 301 table.

COMDENTS .

- Average atom modeling throughout except for ldeal gas portion of nuclear model where ldeal mixing was used.

- TFD as calculated by candide In GRIZZLY was used for the electronic contibution. Chartjd nuclear model with chartd gamma (igrun=1). Gamref adjusted to 0.5 to reproduce ehock data for foamed polygtyrene at initial density of 0.3 . Debkel $=258$, tmelt $=600$. cold curve from shock data and sound velocity. Used us-up composed of 3 stralght lines with up $=0.0,3.25,4.0,7.15$ and $u s=2.0,7.5,7.5,12.0$ respectively. Data from lasl shock compendium. Tfd match made at compression of 2.47 . ecoh=112 calculated from heat of vaporization of carbon and dissociation energy of hydrogen. Faclj=1.0. 301 table has Maxwell constructions.

- No tension region exists.

- Pressure, energy and free energy are tabulated in the 301 table.

EOS NUYBER 7592

MATERIAL, Po.lyotyrene $(Z=3.5, A=6.51)$

SOURCE. J. Barnes, S. Lyon

DATE. NOV 88 (orig data); Jul 92 (modifications)

REFS. None

COMPOSITION. CH

CODES. GRIZZLY

RANGE. 73 densities, $0.0,1.04 \mathrm{E}-6, \ldots, 20880 \mathrm{~g} / \mathrm{cc}$, 41 temperatures, $0.0,145.06,298, \ldots .1 .16 \mathrm{E}+9$ Kelvin.

MODIFICATIONS .

- The 201 table was modified to give PREF=1.013E-4 GPa, 
TREP $=298.152 \mathrm{~K}$ (STP conditions), RREF $=1.044 \mathrm{~g} / \mathrm{CC}$ and BREF $=1.7407$ GPa. The value of BREF corresponds to a sound speed of $1.3016 \mathrm{~km} / \mathrm{s}$.

- No changes were made to the 301 table. CONDENTS .

- Average atom modeling throughout except for lceal gas portion of nuclear model where ideal mixing was used.

- TFD as calculated by candide In GRIZZLY was used for the electronic contibution. Chartjd nuclear model with chartd gamma (igrun=1). gamref $=0.565$, debkel $=222$, tmelt $=510$. Cold curve from shock data and sound velocity. (us, up) data polnts $(0.0,1.898$ ),

$(0.77,3.47)$ $(2.30,6.29),(3.80,7.35),(5.35,9.57)$. In order to match critical

point data, we set ecohkc $=15$ and faclf $=0.20$. In order to get a total pressure of 1 bar at room temperature and normal density, we rescaled the cold curve with rhoo $=1.071$. Tfd match compressionwas 2.268 . 301 table has Maxwell constructions.

- No tension region exists.

- It does not give the correct sound speed at the reference state.

- Pressure, energy and free energy are tabulated in the 301 table.

EOS NUMBER 7601

KATERIAL, EPOXY $(Z=3.2407, A=5.9134)$

SOURCE. J. JOhnson

DATE. July 84 (orig data); Aug 92 (modifications)

REFS. None

COMPOSITION. $c[0.347]$ o[0.048] H[0.577] N[0.028] by number

fraction

CODES. GRIZZLY

RANGE. 69 densities, $0.0,1.18 \theta-6, \ldots 2.37 \theta 4 \mathrm{~g} / \mathrm{Cc}$,

37 temperatures, $0.0,145.06,298.152, \ldots, 1.1609$ Relvin.

MODIFICATIONS.

- The 201 table was modified to give PREF=0.0 GPa, TREF=298.152 K (STP conditions), RREF=1.1853 g/CC and BREF=8.0295 GPa. The value of BREF corresponds to a sound speed of $2.7356 \mathrm{~km} / \mathrm{s}$.

- No changes were made to the 301 table.

COMRENTS.

- Average atom modeling throughout. Tfd as calculated by candide in grizzly was used for electronic contribution. Cold curve obtained from shock data in lasl compendium. Tfa match shifted to compression of 1.9 and ecoh $=57 \mathrm{~mJ}$ per $\mathrm{kg}$. Chartd nuclear and gammodels with gamma $0=0.8$. Thetao found from poisson $=0.333$.

- This EOS has van der Waals loops and no Maxwell constructions. Hence it gives a tension region for use with fracture models but does not describe vaporization correctly.

- There 18 a tension region for temperatures $108 \mathrm{~s}$ than $3000 \mathrm{~K}$.

- Pressure, energy and free energy are tabulated in the 301 table.

EOS NUMBER 7602

MATERIAL, EPOXY $(z=3.2407, A=5.9134)$

SOURCE. J. JOhnson

DATE. Nov 84 (orig data); Aug 92 (modifications)

RERS. None

COMPOSITION. $c[0.347] 0[0.048] \mathrm{H}[0.577] \mathrm{N}[0.028]$ by number

fraction 
CODES. EOSCRAY, CANDIDE

RANGE. 66 densities, $0,0.0,1.320-6, \ldots, 1323 \mathrm{~g} / \mathrm{CC}$,

27 temperatures, $0 ., 0.0,145.06,298.129, \ldots, 1.16 e 9$ Kelvin.

MODIFICATIONS .

- The 201 table was modified to give PREP=1.0130-4 GPa,

TREF $=298.129 \mathrm{~K}$ (STP conditions), RREF $=1.185 \mathrm{~g} / \mathrm{CC}$ and

$B R E=4.011 \mathrm{GPa}$. The value of BREF corresponds to a sound

speed of $1.9019 \mathrm{~km} / \mathrm{s}$.

- No changes were made to the 301 table.

comantwTs.

- This eos is the same modeling as 7601 except maxwell constructions were made. Because we had to switch codes to do the maxwell constructions, emall differences between the two eos's are to be expected. If two-temperature tables are needed for this material, the two-temperature tables from 7601 may be used.

- This EOS has Maxwell constructions with no tension reginn. Note that this results in an incorrect sound speed when interpolating from the tables.

- Only pressure and energy are tabulated in the 301 table. Entropy and free energy are not included.

EOS NUMBER 7610

MATERIAL, BerY111um Oxide $(\mathrm{Z}=6, A=12.506)$

SOURCE. J. Barnes, S. Lyon

DATE. Mar86 (orlg data); Aug 92 (modiflcations)

REFS. LAMS Report

COMPOSITION. BeO

CODES. GRIZZLY

RANGE. 68 densities, $0.0,3.010-6, \ldots, 60200 \mathrm{~g} / \mathrm{CC}$,

37 temperatures, $0.0,145.06,298.152, \ldots, 1.1609$ Kelvin.

MODIFICATIONS .

- The 201 table was modified to give RREF=0.0 GPa, TREF=298.152 K ( STP conditions), RREF $=3.01 \mathrm{~g} / \mathrm{CC}$ and $\mathrm{BREF}=214.215 \mathrm{GPa}$. The value of BREF corresponds to a sound epeed of $8.4591 \mathrm{~km} / \mathrm{s}$.

- No changes were made to the 301 table.

comarests.

- Constructed with modified morse cold curve, cowan nuclear model and 3-coefficient virial match. Electronic thermal contribution was obtained from average-atom tfd calculations. Calculated shock hugonlot 18 in good agreement with experimental data above 400 kbar. Shock data at lower stresses shows effects of extremely high hugoniot elastic limit. Calculated vapor pressures are in fair agreement with limited experimental values available.

- This EOS has van der Waals loops and no Maxwell constructions. Hence it gives a tension region for use with fracture models but does not describe vaporization correctly.

- There 18 a tension region for temperatures 1ess than $9000 \mathrm{~K}$.

- Pressure, energy and free energy are tabulated in the 301 table.

EOS NUMBER 7750

MATERIAL, Lucite $(z=3.6, A=6.674)$

SOURCE. J. Barnes, S. Lyon

DATE. Dec 88 (orig da a); Aug 92 (modifications)

REFS. None

COMPOSITION, $\mathrm{C5H} 8 \mathrm{H} 2$

CODES . GRIZZLY 
Sandia EOS Data Base

Ruros. 73 densities, $0.0,1.190-6, \ldots, 2.3704 \mathrm{~g} / \mathrm{cc}$, 37 tomperatures, $0.0,145.06,298.152, \ldots, 1.1609$ Kelvin.

MODIEICATIONS.

- The 201 table was modifled to give PREF=1.0130-4 GPa, TREF $=298.152 \mathrm{~K}$ (STP conditions), RREF=1.186 g/cc and $B R E F=1.94084 \mathrm{GPa}$. The value of BREF corremponde to a sound apeed of $1.298 \mathrm{~km} / \mathrm{m}$.

- No changes were made to the 301 table.

conctirss.

- Average atom modeling throughout except for Ideal gas portion of nuclear model where ldeal mixing was used. Tfd as calculated by candide in grizziy was used for the electronic contribution. Chartfd nuclear model with chartd gamma (1grun=1). Gamref = 1.12 , dobkel $=222$, tmelt $=443$. cold curve from shock data and sound velocity. (up,us) data points $(0.0,2.223),(0.50,3.40)$, $(2.90,7.09),(3.24,7.33),(5.25,9.80)$. In order to match critical point data, we set ecohkc $=15$ and faclf $=0.17$. In order to get a total pressure of 1 bar at room temperature and normal density, we rescaled the cold curve with rhoo $=1.21705$. Tfd match compression was 2.154. 301 table has maxwell constructions.

- There is no a tension region - sound speed from interpolation on table is probably not accurate.

- Pressure, energy and free onergy are tabulated in the 301 table.

BOS NUYBER 7931

MATERIAL. Sylgard 184 (s111cone rubber) ( $z=4.2, a=7.84$ )

SOURCE. F. DOWell

DATE. MaY 85

REFS. IAMS report, to be published

COMPOSITION. wt\% - C(30.9), H(7.4), $s 1(37.8), \mathrm{O}(23.9)$. approximate formula - $\mathrm{SI}(\mathrm{CH} 3) 20$.

CODES. GRIZZLY, EIXTB32

RANGE, 68 densities, $0,1 . \mathrm{E}-6,1 . \mathrm{E}-5, \ldots, 2.1 \mathrm{E}+3 \mathrm{~g} / \mathrm{CC}$,

33 temperatures, $0,100,200,298.15, \ldots, 1.2 \mathrm{Eg}$ Kelvin. MODIFICATIONS

The 201 table ras modifled to give $R R E F=1.0373$, TREF=298.15, and BREF=2.6270 GPa. The 301 table predicts a sound speed of 1.884 . No changes were made to the 301 table.

comadarts.

- Th1s EOS does not have Maxwell constructions and so has a tension region for temperatures below $400 \mathrm{~K}$. Between 400 and $900 \mathrm{~K}$, the pressures are not monotonic below normal density, although the EOS does not actually go into tension.

- Pressure, energy, and free energy are tabulated in the 301 table. 


\section{Distribution}

\section{External Distribution}

Stanley Klein, M2/321

The Aerospace Corp.

PO Box 92957

Los Angeles, CA 90009-2957

G. R. Johnson

Alliant Techsystems Inc.

7225 Northland Dr.

Brooklyn Park, MN 55428

Eric Peterson

MN11-2720

Alliant Techsystems, Inc.

600 Second St., NE

Hopkins, MN 55343

M. Alme

Alme and Associates

102 Stevens Forest Professional Center

9650 Santiago Road

Columbia, MD 21045

J. Walker

Amparo Corporation

P. O. Box 2687

Santa Fe, NM 87504

Frank Maestas

Principal Engineer

Applied Research Associates

4300 San Mateo Blvd.

Suite A220

Albuquerque, NM 87110

Richard Zernow

Applied Research Associates

714 West Jefferson Ave.

Suite 305

Lakewood, CO 80235

Howard Chung

Argonne National Laboratory

$\mathrm{RE} / 331$

9700 South Cass Avenue

Argonne, IL 60439-4817
Ernest L. Baker

Bldg 3022, SMCAR-AEE-WW

U. S. Army ARDEC

Picatinny Arsenal, NJ 07806-5000

Kent Kimsey (2)

U.S. Army Research Laboratory

AMSRL-WT-TC

Aberdeen Proving Ground, MD 21005-5066

Attn: K. Kimsey, J. Zukas

John Tipton

U. S. Army Engineer Division

HNDED-SY

PO Box 1600

Huntsville, AL 35807

R. Rohani

U.S. Army Engineer Waterways Experiment

Station

Attn: CEWES-SD

3909 Halls Ferry Road

Vicksburg, MS 39180-6199

Shun-chin Chou

Army Materials Technology Laboratory

SLCMT-MRD

Watertown, MA 02172-0001

George Snyder

U. S. Army Missile Command

AMSMI-RD-ST-WF

Redstone, Arsenal, AL 35898-5247

David Tenenbaum

U. S. Army Tank Automotive Command

RD\&E Center

Survivability Division

Mail Code MASTA-RSS

Warren, MI 48397-5000

Doug Everhart

Battelle Memorial Institute

505 King Ave.

Columbus, OH 43201-2693 
Glen Salo

BDM Corporation

1801 Randolph Road SE

Albuquerque, NM 87106

Richard Beyer

Bettis Atomic Power Laboratory

Westinghouse Electric Company

Box 79

West Mifflin, PA 15122-0079

Steven Bishop

Belvoir RD\&E Center

STRBE-NAA

Fort Belvoir, VA 22060-560

Kevin Housen (2), MS 87-60

The Boeing Company

PO Box 3999

Seattle, WA 98124

Attn: K. Housen, R. Schmidt

S. Schuster

California Research \& Technology

20943 Devonshire St.

Chatsworth, CA 94588

Dennis L. Orphal

California Research \& Technology, Inc.

5117 Johnson Dr.

Pleasanton, CA 94588

Mark Majerus

California Research and Technology, Inc.

PO Box 2229

Princeton, NJ 08543-2229

Mark Smith

Aerophysics Branch

Calspan Corporation/AEDC Operations

MS 440

Arnold AFB, TN 37389

G. Lyles

CIA

6219 Lavell Ct.

Springfield VA 22152
John Walton

OSWR

CIA

Washington, DC 20505

Carlos Marino

Industry, Science, and Technology Department

Cray Research Park

655 E. Lone Oak Dr.

Eagan, MN 55121

Stanley Willner

David Taylor Research Center

Mail Code 3510

Bethesda, MD 20084

Major Robert Kocher

Defense Advanced Research Projects Agency

3701 North Fairfax Drive

Arlington, VA 22203-1714

Michael E. Giltrud

DNA/SPSD

6801 Telegraph Rd.

Alexandria, VA 22310

Randy Hanson

Denver Research Institute

University Park

Denver, CO 80208

Brian Scott

EI Dupont de Demours and Company

Chestnut Run - CR702

Wilmington, DL 19898

William Flis

DynaEast Corporation

3201 Arch Street

Philadelphia, PA 19104

Tien Chou

EG\&G Mound

PO Box 3000

Miamisburg, OH 45343

Julius W. Enig

Enig Associates, Inc.

11120 New Hampshire Ave., Suite 500

Silver Spring, MD 20904-2633 
Kim Parnell

Failure Analysis Associates, Inc.

149 Commonwealth Ave.

P. O. Box 3015

Menlo Park, CA 94025

Vensen Wu

FMC Corporation

MS-P95

2890 De La Cruz Blvd.

Santa Clara, CA 95052

Kenneth Lockwood

Knolls Atomic Power Laboratory

General Electric Company

PO Box 1072

Schenectady, NY 12301-1072

James MacDonald

General Research Corporation

PO Box 6770

Santa Barbara, CA 93160-6770

Guy Spitale

Jet Propulsion Laboratory

California Institute of Technology

Reliability Engineering Section

4800 Oak Grove Drive

Pasadena, CA 91109

Jeff Elder

Kaman Sciences Corporation

Huntsville Office

P. O. Box 2486

Huntsville, AL 35804-2486

John May

Kaman Sciences Corporation 1500 Garden of the Gods Road

Colorado Springs, CO 80933

Thomas Grondzik

Kendall Square Research

2102 Business Center Drive, Suite 115D

Irvine, CA 92715
Ed Cykowski

Lockheed Engineering and Space Company

Mail Code B22

2400 NASA Road 1

Houston, TX 77058-3711

Erik Matheson (2)

O/81-12 B/157

Lockheed Missiles \& Space Company

1111 Lockheed Way

Sunnyvale, CA 94088-3504

Attn: Y.-I. Choo, E. Matheson

Richard Crawford

Logicon RDA

P. O. Box 92500

Los Angeles, CA 90009

John Flowers

LTV Missiles and Electronics Group

P. O. Box 650003

M/S EM-36

Dallas, TX 75265-0003

Tim Gillespie

MS H4330

Martin Marietta Astronautics Group

PO Box 179

Denver, CO 80201

George Christoph

Martin Marietta Laboratories

1450 S. Rolling Road

Baltimore, Maryland 21227

Larry Williams

Martin Marietta

MP 126

Box 5837

Orlando, FL 32855

N. A. Louie

Department Y831, Mail Station 13-3

McDonnell Douglas Missile Space Systems

Company

5301 Bolsa Avenue

Huntington Beach, CA 92647 
Eric Christiansen

NASA Johnson Space Center

Space Science Branch/SN3

Houston, TX 77058

Scott Hill

NASA Marshall Space Flight Center Mail Code ED52

Redstone Arsenal

Huntsville, AL 35812

John M. Pipkin (Code 4310)

Naval Coastal Systems Center

Thomas Drive

Panama City Beach, FL 32405-5000

Hans Mair

Naval Surface Warfare Center

10901 New Hampshire Ave.

Silver Spring, MD 20903-5000

Dan Bowlus

Naval Underwater Systems Center

Mail Code 8123

Newport, RI 02841-5047

Eric Lundstrom

Code 3261

Naval Weapons Center

China Lake, CA 93555

Mark Walz

NMI

2229 Main Street

Concord, MA 01742

Firooz Allahdadi

Phillips Laboratory

PL/WSSD

Kirtland AFB, NM 87117-6008

Ray Pierce

Physics International

PO Box 5010

San Leandro, CA 94577-0599
Keith Pauley

PNL

KS-42

P. O. Box 999

Richland, WA 99352

Steve Rieco

POD Associates, Inc.

2309 Renard Place, SE

Suite 201

Albuquerque, NM 87106

C. W. Nestor, Jr.

Oak Ridge National Laboratory

PO Box 2009

Oak Ridge, TN 37831-8058

Anthony Gurule

Orion International Inc.

Suite 200

300 San Mateo NE

Albuquerque, NM 87108

Tracy Christian-Frear

Re/Spec, Inc., Suite 300

4775 Indian School Rd. NE

Albuquerque, NM 87110

Greg L. Savoni

Rockwell International Corporation

12214 Lakewood Blvd.

NA-40

Downey, CA 90241

R\&D Associates

6053 West Century Boulevard

P.O. Box 92500

Los Angeles, CA 90009

Attn: B. Lee

Mark Fry

SAIC/New York

8 West 40th Street

14 Floor

New York, New York 10018

Ronald Weitz

SAIC

2109 Air Park Road SE

Albuquerque, NM 87106 
James Zerkle

SAIC

Suite A

11696 Sorrento Valley Road

San Diego, CA 92121

Charles E. Needham

Maxwell/S-CUBED

2501 Yale SE

Suite 300

Albuquerque, NM 87106

Steve Peyton

S-CUBED

P. O. Box 1620

LaJolla, CA 92038-1620

C. E. Anderson

Southwest Research Institute

P.O. Drawer 28510

San Antonio, TX 78284

William G. Tanner

Space Science Laboratory

P. O. Box 97303

Waco, TX 76798

Bhuminder Singh

Teledyne Brown Engineering Cummings Research Park

300 Sparkman Dr., NW

PO Box 070007

Huntsville, AL 35807-7007

Steve Herrick

Textron Defense Systems

Mail Stop 1115

201 Lowell St.

Wilmington, MA 01887

Dwight Clark, Mailstop 280

Thiokol Corporation

Advanced Technology Division

P. O. Box 707

Brigham City, Utah 84302
Akhilesh Maewal

Trans-Science Corporation

7777 Fay Avenue

Suite 112

La Jolla, CA 92037

Stan Fink, R1/1044

TRW

One Space Park

Redondo Beach, CA 90278

T. P. Shivananda

TRW Ballistic Missiles Group

SB/2/1011

P. O. Box 1310

San Bernardino, CA 92402-1310

Brent Webb

Umpqua Research Company

P. O. Box 791

125 Volunteer Way

Myrtle Creek, OR 97457

Gene Carden

University of Alabama

PO Box 870278

Tuscaloosa, AL 35487-0278

Gary Hough

Aerophysics Research Facility

University of Alabama at Huntsville

Huntsville, AL 35899

David J. Benson

Dept. of AMES R-011

University of California San Diego

La Jolla, CA 92093

Robert Culp

Department of Aerospace Engineering Sciences

Campus Box 429

University of Colorado

Boulder, CO 80309

Garry Abfalter

Impact Physics Group

University of Dayton Research Institute

300 College Park, Room KLA 14

Dayton, OH 45469-0182 
Chen-Chi Hsu

University of Florida

nepartment of Aerospace Engineering

231 Aerospace Building

Gainesville, FL 32611

Thomas Moriaty

Department of Engineering Sciences and

Mechanics

University of Tennessee

Knoxville, TN 37996-2030

Stephan J. Bless

The University of Texas at Austin

Institute for Advanced Technology

4030-2 W. Braker Lane, Suite 200

Austin, TX 78712

Eric Fahrenthold

Department of Mechanical Engineering

The University of Texas at Austin

Austin, TX 78712

Keith Holsapple

Department of Aeronautics and Astronautics

FS10

The University of Washington

Seattle, WA 98195

John A. Collins

Wright Laboratory

WL/MNMW

Eglin AFB, FL 32542-5434

Dan Brubaker

Wright Laboratory

WL/MNSA

Eglin AFB, FL 32542-5434

University of California (2)

Lawrence Livermore National Laboratory

7000 East Ave.

P.O. Box 808

Livermore, CA 94550

Attn: A. Attia, MS L- $\approx 00$

Attn: W. Moran, MS L-200
Los Alamos National Laboratory (9)

Mail Station 5000

P.O. Box 1663

Los Alamos, NM 87545

Attn: J. Abdallah, MS-B212

Attn: T. F. Adams, MS F663

Attn: B. I. Bennett, MS B221

Attn: R. A. Clark, MS B257

Attn: C. W. Cranfill, MS-B257

Attn: K. S. Holian, MS B295

Attn: J. W. Hopson, MS B216

Attn: J. D. Johnson, MS-B221

Attn: G. K. Straub, MS-B221

\section{Sandia Internal}

$\begin{array}{ll}1425 & \text { J. H. Biffle } \\ 1431 & \text { J. M. McGlaun } \\ 1431 & \text { K. G. Budge } \\ 1431 & \text { D. Campbell } \\ 1431 & \text { M. G. Elrick } \\ 1431 & \text { E. S. Hertel } \\ 1431 & \text { R. J. Lawrence } \\ 1431 & \text { J. S. Peery } \\ 1431 & \text { S. V. Petney } \\ 1431 & \text { A. C. Robinson } \\ 1431 & \text { T. G. Trucano } \\ 1431 & \text { M. Wong } \\ 1431 & \text { CTH Day File } \\ 1432 & \text { P. Yarrington } \\ 1432 & \text { R. L. Bell } \\ 1432 & \text { R. M. Brannon } \\ 1432 & \text { P. J. Chen } \\ 1432 & \text { H. E. Fang } \\ 1432 & \text { A. V. Farnsworth } \\ 1432 & \text { G. I. Kerley (10) } \\ 1432 & \text { M. E. Kipp } \\ 1432 & \text { F. R. Norwood } \\ 1432 & \text { S. A. Silling } \\ 1432 & \text { P. A. I dylor } \\ 1433 & \text { P. L. Stanton } \\ 1433 & \text { M. Boslough } \\ 1433 & \text { L. C. Chhabildas } \\ 1433 & \text { M. D. Furnish } \\ 1433 & \text { D. E. Grady } \\ 1434 & \text { D. Martinez } \\ 1511 & \text { J. S. Rottler } \\ 1512 & \text { A. C. Ratzei } \\ & \end{array}$




$\begin{array}{ll}1513 & \text { R. D. Skocypec } \\ 1553 & \text { W. L. Hermina } \\ 1561 & \text { H. S. Morgan } \\ 1562 & \text { R. K. Thomas } \\ 6418 & \text { S. L. Thompson } \\ 6418 & \text { L. N. Kmetyk } \\ 6515 & \text { M. Berman } \\ 6515 & \text { K. Boyack } \\ 8741 & \text { G. A. Benedetti } \\ 8741 & \text { M. L. Chiesa } \\ 8741 & \text { L. E. Voelker } \\ 8742 & \text { J. J. Dike } \\ 8243 & \text { M. L. Callabresi } \\ 9311 & \text { A. J. Chabai } \\ 9311 & \text { T. Bergstresser }\end{array}$

8523-2 Central Technical Files

7141 Technical Libarary (5)

7151 Technical Publications

7613-2 Document Processing for DOE/OSTI

(10) 

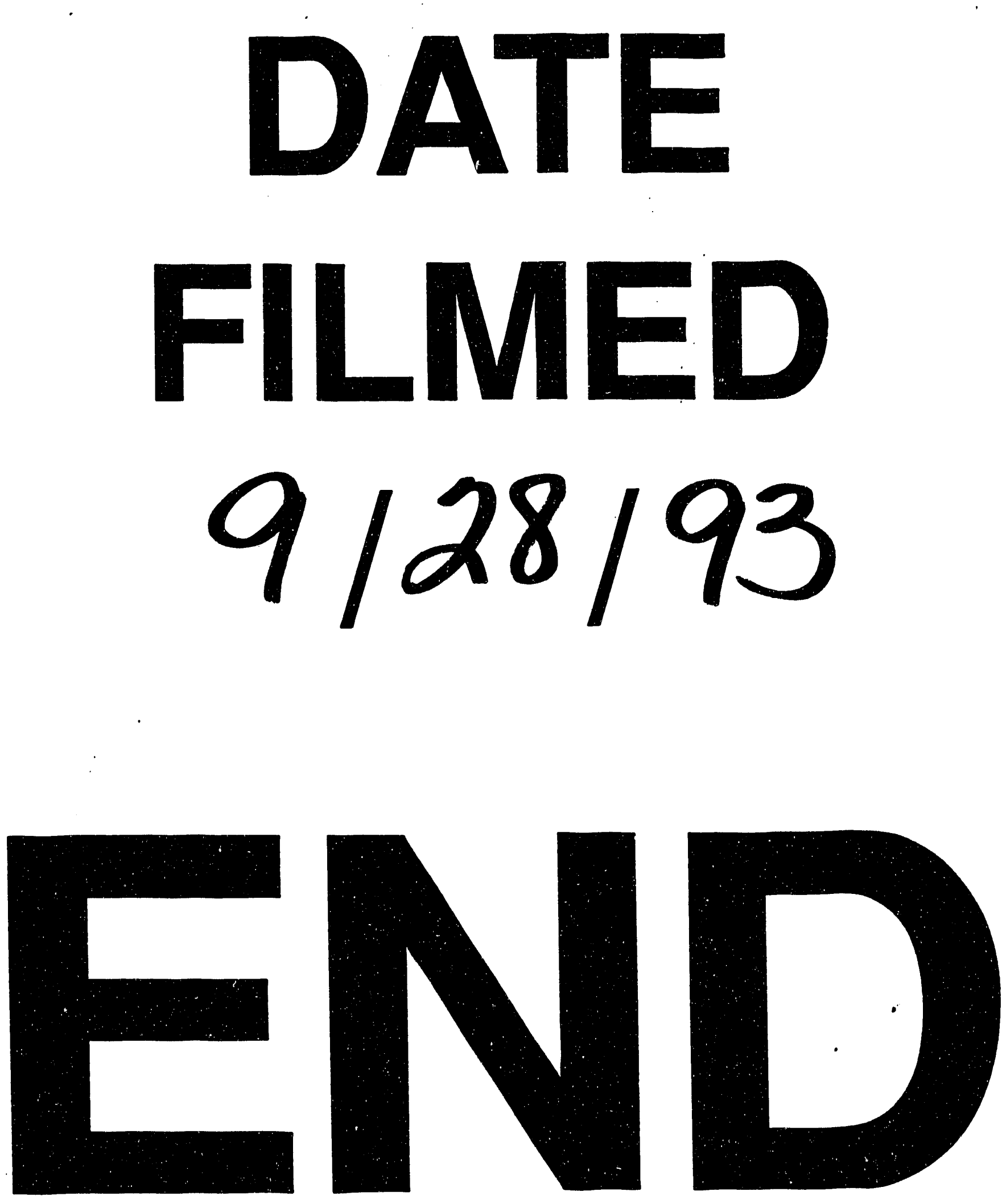
